\title{
Review
}

\section{A molecular perspective on terpene variation in Australian Myrtaceae}

\author{
Andras Keszei ${ }^{\mathrm{A}}$, Curt L. Brubaker ${ }^{\mathrm{B}, \mathrm{C}}$ and William J. Foley ${ }^{\mathrm{D}}$

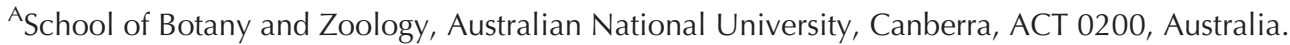 \\ ${ }^{B}$ CSIRO Division of Plant Industry, Black Mountain, Canberra, ACT 2601, Australia. \\ Cresent address: Bayer BioScience N.V., Technologiepark 38 B-9052, Gent, Belgium. \\ ${ }^{\mathrm{D}}$ Corresponding author. Email: william.foley@anu.edu.au
}

\begin{abstract}
The terpenoid-dominated essential oils in Australian Myrtaceae mediate many ecological interactions and are important industrially. Of all the significant essential oil-producing families, Myrtaceae is the only one for which there is no molecular information on terpene biosynthesis. Here we summarise available knowledge on terpene biosynthesis and its relevance to the Myrtaceae to provide a foundation for ecological and genetic studies of chemical diversity. There are several steps in the terpene biosynthesis pathway that have potential for influencing the oil yield, profile and composition of leaf oils in Myrtaceae. The biochemical steps that influence oil yield in Myrtaceae probably occur in the steps of the pathway leading up to the synthesis of the terpene backbone. Qualitative differences in oil profiles are more likely to be due to variation in terpene synthases and terpene-modifying enzymes. Most of the information on molecular variation in terpene biosynthesis is based on the analysis of artificially derived mutants but Australian Myrtaceae can provide examples of the same mechanisms in an ecological context.
\end{abstract}

\section{Introduction}

One of the most distinctive features of Australian Myrtaceae is their high content of terpene-dominated essential oils. These oils are complex mixtures of $\mathrm{C}_{10}$ and $\mathrm{C}_{15}$ terpenes and other volatile constituents, which have distinct aromas and are responsible for the characteristic scent of Australian forests. Although there have been many studies of the terpenes of the Australian flora, nearly all have been aimed at cataloguing the chemical diversity present (Boland et al. 1991; Brophy and Southwell 2002). However, there is little understanding of how genetic variation interacts with environmental conditions to produce different types and quantities of terpenes. Terpenes are important in interactions among plants and between plants and animals, making variation of these foliar chemicals ecologically significant.

Within Eucalyptus, terpenes have been implicated in many ecological interactions. They have roles as deterrents to feeding and reproduction of insect herbivores (Morrow and Fox 1980; Edwards et al. 1990, 1993; Stone and Bacon 1994), attractants or repellents to vertebrate herbivores (Southwell 1978; Hume and Esson 1993), cues that indicate the presence of other toxic constituents (Lawler et al. 1999), mediators of resistance to fungal infection (Eyles et al. 2003), allelopathic agents (Alves et al. 2004), attractants for parasitoids and pollinators (Giamakis et al. 2001) and determinants of leaflitter decomposition rates (Molina et al. 1991). Terpenes are also thought to influence variation in soil mineralisation rates and understorey biodiversity (Iason 2005), as well as significantly contributing to the level of atmospheric hydrocarbons (He et al. 2000a).

Terpenes have also been used widely as taxonomic characters in the Myrtaceae (Brophy et al. 1994; Doran et al. 1995; Dunlop et al. 1999). Chemical polymorphism is useful for taxonomic purposes only if it corresponds clearly to a genetic difference. Molecular studies into the biosynthesis of terpenes are essential to establish the link between chemical and genetic variation.

Variations in terpene profiles are also significant to industry, as Australia produces essential oils from several species of Eucalyptus and Melaleuca (Southwell and Lowe 1999; Brophy and Southwell 2002). As stricter standards are being set on the composition of essential oils used by the food and pharmaceutical industries, better knowledge of the genetic and environmental determinants of chemical variation would help to reduce the effort currently spent on breeding, refining and separation (Brophy and Southwell 2002; Anon. 2004). In addition, terpenes are among a suite of economic products being developed from oil mallee (e.g. E. polybractea and E. loxophleba) plantations used for revegetation in salt-affected areas of Western Australia (Wildy et al. 2000; Bell et al. 2001).

Thus, understanding the causes of terpene variation from Myrtaceous plants is of interest to ecologists, taxonomists and natural products industries. Recent studies in other plant families (mainly Lamiaceae, Rutaceae and Abietaceae) have demonstrated that molecular genetics can begin to explain how the complex terpene mixtures found in most essential oils are 
assembled (Gershenzon and Croteau 1993; Bohlmann et al. 1998a; Martin et al. 2004).

The aim of the present review is to provide a molecular perspective on chemical variation in the terpenoid leaf oils of Australian Myrtaceae, to provide a basis for molecular and ecological studies of chemical variation in Australian plants. We start by describing the current understanding of terpene biosynthesis in other organisms and the patterns of variation that have been described in leaf oils from Myrtaceae. We then discuss the extent to which we can expect correlations between chemical data and genetic processes, on the basis of studies in other species, and identify the molecular elements that need to be studied in order to understand the patterns of chemical variation that have been described.

\section{What are terpenes?}

Terpene nomenclature (i.e. hemi-, mono-, sesqui-, di-, tri- and tetraterpenes) refers to the number of carbon atoms in the terpene backbone (Fig. 1). Classification of organic compounds as terpenes depends on their biosynthetic origin, rather than on carbon number or molecular structure. For example, bisabolol and abscisic acid show similar structures; namely, both contain 15-carbon atoms, comprising a six-membered monounsaturated ring and acyl sidechains (Fig. 1). Despite these similarities, the origin of the carbon backbone places the former among the sesquiterpenes and the latter among the apocarotenoids (Milborrow 2001). Within each of the main groups, we can distinguish between terpene hydrocarbons, terpene alcohols, ketones, aldehydes, acids, esters, lactones and also acyclic, monocyclic and polycyclic terpenes. These categories, however, do not necessarily imply common biosynthetic origins.

Although terpenes can be found as simple compounds, they also occur as components of more complex structures. Terpenes form complexes with acetate and other carboxylic acids, iridoids (Wink 2003), simple sugars (Lücker et al. 2001) and polyketides (Yamakoshi et al. 1992; Eschler et al. 2000; de Meijer and Hammond 2005). In Myrtaceae, polyketides called formylated phloroglucinol compounds (FPCs) occur frequently as conjugates of terpenes (Ghisalberti 1996; Eschler et al. 2000). The main types of terpene-FPC complexes found in Myrtaceae are macrocarpals and euglobals.

\section{Terpenes in primary and secondary metabolism}

Primary metabolism involves biochemical processes necessary for maintaining life functions such as structure, assimilation, cellular respiration, regulation and reproduction. Of these processes, terpenes are significant in the following three main roles: (i) as components of cell membranes (sterol type triterpenes); (ii) as components of photosystem I and II (carotenoid tetraterpenes and diterpenoid phytol chains of chlorophylls) and (iii) as phytohormones (e.g. gibberellin (of a diterpenoid origin) and abscisic acid (of tetraterpenoid origin). The terpenes involved in processes of primary metabolism are generally non-volatile, contain 20 or more carbon atoms and are responsible for maintaining intracellular structure, and assimilative and regulative processes.

Whereas primary metabolism is the collective term used for all the chemical components in an organism involved with maintaining basic life processes, all products of biosynthesis not related to these are classified as secondary metabolites. Even though secondary compounds are a normal and integral part of the metabolism of plants, their synthesis is often regulated independently of primary metabolic processes, or compartmentally separated in specialised cells or storage organs. All classes of terpenes are represented in secondary metabolism, either by themselves or appearing as components of more complex compounds. The boundary between primary and secondary metabolism is not easily defined. For example, monoterpenes have been shown to have a significant effect in increasing the thermotolerance of Photosystem II (Copolovici et al. 2005). Therefore, the function of a monoterpene within a plant could depend on the environmental and biotic context. A given terpene could be essential to maintain photosynthesis in summer, whereas in the cooler months, when there is little need for thermoprotection, it may serve mainly as a deterrent to herbivores. Understanding the biological functions of the different types of terpenes is essential in understanding the molecular basis of their variation.

\section{The terpene biosynthesis pathway}

\section{The biosynthesis of terpene precursors}

The individual branches of the terpene biosynthesis pathway correspond to the different classes of terpenes (Fig. 2). Hemi-, mono-, sesqui-, di-, tri- and tetraterpenes, representing 5-, 10-, 15-, 20-, 30- and 40-carbon atom compounds, all require different substrates and enzymes for their biosynthesis. Isopentenyl diphosphate (IDP, Fig. 2) is the simplest common precursor dedicated to terpene biosynthesis and surprisingly it has been shown to be synthesised in parallel via two independent and compartmentally separated pathways (Eisenreich et al. 1998). The mevalonate (MVA) pathway is localised in the cytoplasm. It uses acetyl-CoA from the Krebs cycle, via mevalonic acid, and supplies sesqui- and triterpene precursors. The deoxyxylulose phosphate (DXP) pathway is localised in the plastid and uses glyceraldehyde phosphate from the Calvin cycle, via deoxyxylulose phosphate, and provides IDP mainly for the synthesis of hemi-, mono-, di-and tetraterpenes. In the production of monoterpenes in peppermint (Mentha $\times$ piperita), it has been shown that the main limiting steps in obtaining high oil yields were the early elements of the DXP pathway and removing these bottlenecks through the production of transgenic plants increased the yield by more than $100 \%$ (Wildung and Croteau 2005). In the production of sesquiterpenes, similar bottlenecks may be expected along the MVA pathway. The MVA and DXP pathway genes therefore provide suitable candidates for the study of major quantitative variation in foliar terpene concentration.

Both the MVA and DXP pathways lead to the production of IDP and its isomer dimethyl-allyl diphosphate (DMADP), which in turn, are required for prenyl diphosphate synthesis. The prenyl diphosphates produced are geranyl diphosphate (GDP), used for the synthesis of monoterpenes; farnesyl diphosphate (FDP), used in the biosynthesis of sesqui- and triterpenes; and geranylgeranyl diphosphate (GGDP), used in the biosynthesis of di- and tetraterpenes. The synthesis of the individual prenyl diphosphates requires specific ratios of IDP 
hydrocarbons

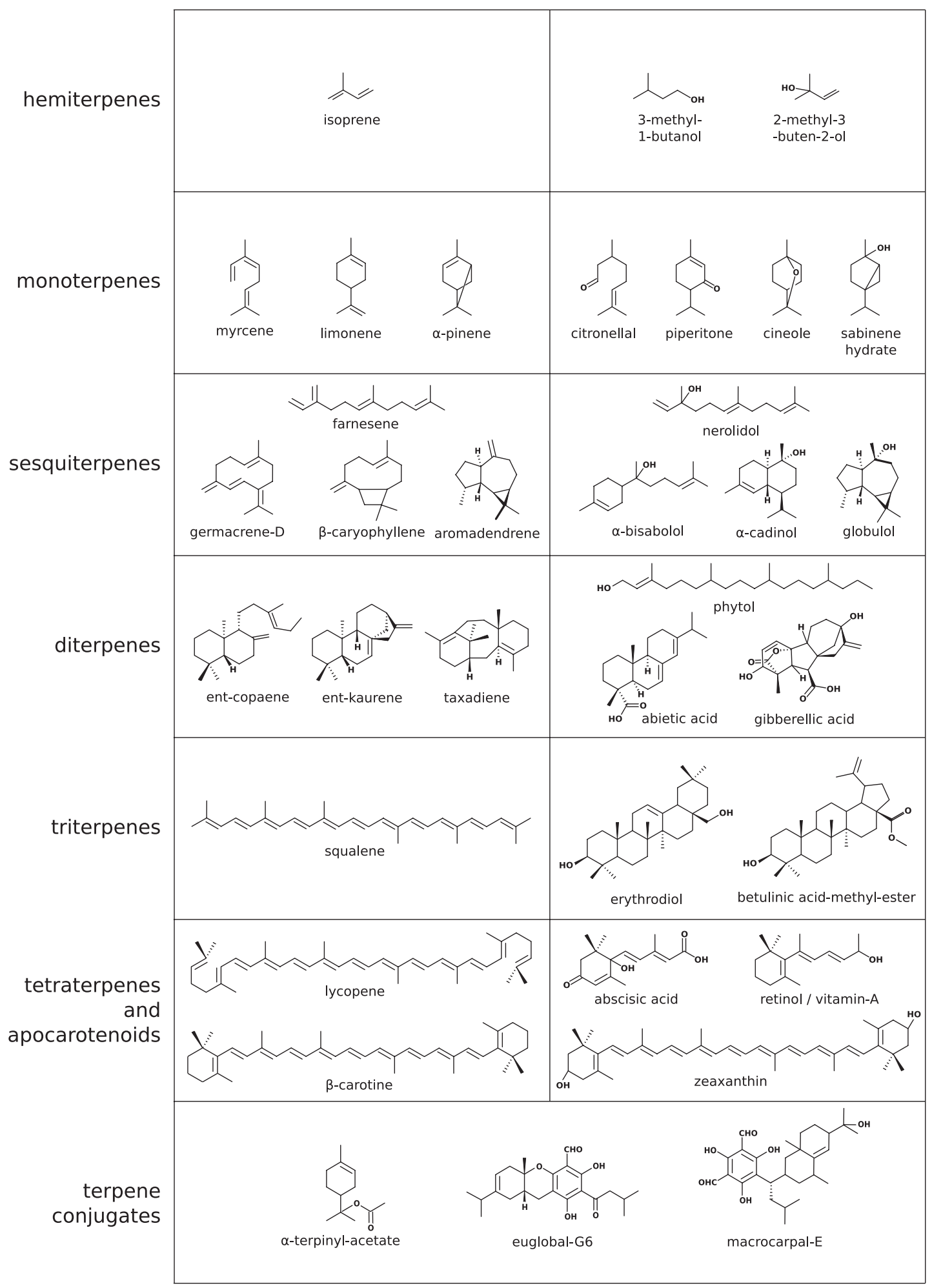

Fig. 1. Representatives of the main classes of terpenes, showing acyclic, monocyclic and polycyclic representatives of both terpene hydrocarbons and oxygenated terpenes. 


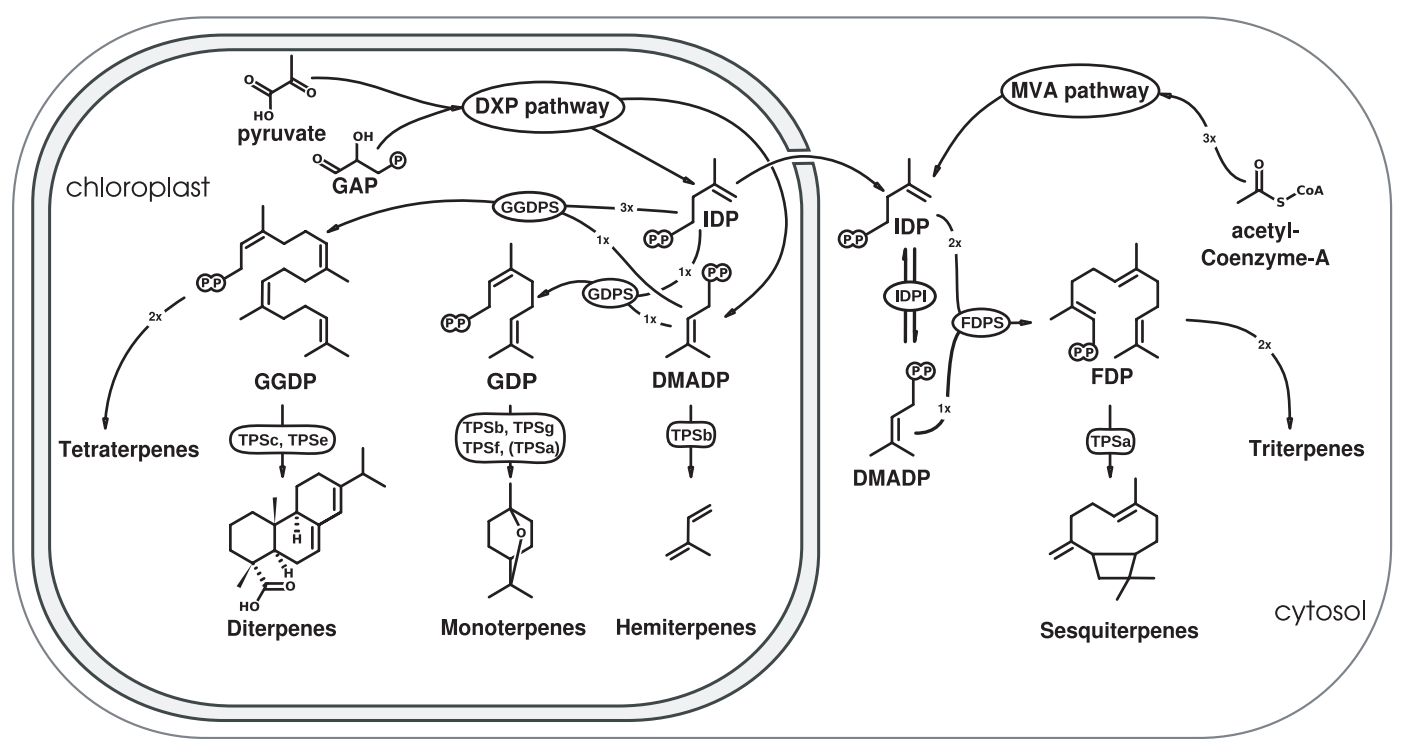

Fig. 2. Terpene synthesis in the plant cell, starting from the first dedicated step in both the cytosolic and plastidic pathways. Primary metabolites are highlighted, enzymes and enzyme groups are circled, and reaction stoichiometry is indicated on the reaction arrows.

and DMADP. GDP synthases utilise IDP and DMADP in a $1: 1$ ratio (Bouvier et al. 2000) and FDP synthases use the two isomers in a $2: 1$ ratio, respectively (Hugueney and Camara 1990), whereas GGDP synthases require three IDP molecules for every DMADP molecule (Allen and Banthorpe 1981; Ohnuma et al. 1989) (Fig. 2). To obtain the optimal ratio in each specific tissue, isopentenyl diphosphate isomerases (IDPI) catalyse the conversion of IDP to DMADP. Both plastidic and cytosolic forms exist and have been isolated from Melaleuca alternifolia (Shelton et al. 2004a). This gene family is involved in resource allocation to the different branches of terpene biosynthesis; therefore, variation in these genes has also been shown to affect the overall composition of foliar terpenes (Wildung and Croteau 2005).

\section{The biosynthesis of the terpene backbone}

All the previously described processes, incorporating different compounds, compartments and biosynthetic pathways, culminate in the synthesis of a terpene skeleton. This step is catalysed by a single family of enzymes, the terpene synthases (TPS), irrespective of the specific substrate used or the organellar localisation of the reaction.

The first step in this reaction is the coordination of the negatively charged diphosphate ion by three $\mathrm{Mg}^{2+}$ ions joined to aspartate residues of the active site, creating a prenyl carbocation which is still associated with the diphosphate group (Fig. 3a, b) (Starks et al. 1997; Whittington et al. 2002). This initial step leads to a change in structure in both the substrate and the active site of the enzyme, which will lead to the subsequent structural rearrangements of the prenyl carbocation into acyclic, monocyclic and bicyclic (Fig. 3a,b) cation structures.

The final step is the stabilisation of the carbocation by deprotonation or by addition of water coupled with deprotonation. In this step, reaction conditions and features of the active site can also determine the stabilisation of the carbocation into the $\alpha$ - or $\beta$ - type skeleton and also whether the final product will be a terpene hydrocarbon or a terpene alcohol.

The different carbocation intermediates and stabilisation reactions may result in the synthesis of multiple products by a single enzyme. A single terpene synthase may be capable of catalysing the conversion of GDP to 10 individual products, not including different enantiomers (Table 1). However, terpene synthases that are strictly product-specific are also known. Examples include geraniol synthase from Cinnamomum tenuipilum (Yang et al. 2005) and Ocimum basilicum (Iijima et al. 2004) and the 1,8-cineole, limonene and E- $\beta$-ocimene synthases from Citrus unshiu (Shimada et al. 2005).

Terpene synthases have been assigned to subfamilies by Bohlmann et al. $(1998 a, 1998 b)$ based on a criterion of $40 \%$ amino acid sequence identity. This widely recognised system generally coincides with functional similarities (Bohlmann et al. $1998 a, 1998 b$ ). The subfamilies of the terpene synthases are introduced below.

\section{Classification of terpene synthase enzymes}

\section{TPSa: angiosperm sesquiterpene synthases}

Angiosperm sesquiterpene synthases belong to the TPSa subfamily. These enzymes are known to be active in the cytoplasm and utilise FDP generated by the cytosolic MVA pathway. Some also show monoterpene synthase activity in the presence of GDP; however, enzyme activity is significantly lower than when using FDP (Mercke et al. 1999).

\section{TPSb: angiosperm monoterpene synthases}

The TPSb subfamily contains most of the angiosperm monoterpene synthases and genes belonging to this group have been identified and characterised from an increasing number of families, including the Lamiaceae, Salicaceae, 
Rutaceae, Brassicaceae, Vitaceae and Asteraceae. Monoterpene synthases of this subfamily are responsible for the conversion of GDP into the bulk of the monoterpenes found in vegetative organs, whereas other subfamilies (TPSf and TPSg) are involved in synthesising floral volatiles.

We have used the example of pinene biosynthesis to illustrate the complexity of the synthesis of a wide variety of monoterpenes in Table 1 , as $\alpha$ - and $\beta$-pinene are the most frequently occurring products of monoterpene synthases characterised. The most prolific of the enzymes capable of pinene synthesis is $\alpha$-terpineol synthase from Vitis vinifera, with 10 possible biosynthesis products in vitro (Martin and Bohlmann 2004). These include both hydrocarbons and oxygenated terpenes. Different synthases produce $\alpha$ - and $\beta$-pinene in different proportions, providing a chemical fingerprint that is characteristic of the particular enzyme (Table 1). Unfortunately, identifying this fingerprint in the essential oil may not always be possible because if multiple enzymes contribute to the total pinene concentration, the ratios of the components will no longer reflect the action of individual enzymes.

Some members of the TPSb subfamily convert DMADP into isoprene or other hemiterpenes (Fig. 2). The isoprene synthases from Pueraria montana (Sharkey et al. 2005) and Populus alba $\times$ tremula (Silver and Fall 1995) are a sister group to the rest of TPSb based on protein alignments (Sharkey et al. 2005). They cluster with a putative limonene synthase from M. alternifolia (Shelton et al. 2004b), which has also been implicated as an isoprene synthase based on individual amino acid motifs (Sharkey et al. 2005). Based on our current knowledge of Myrtaceae, we can expect the leaf oils of Myrtaceae to be synthesised by the terpene synthase subfamilies TPSa and TPSb.

\section{TPSf and TPSg: floral monoterpene synthases}

The TPSf and TPSg monoterpene synthases are thought to be exclusively active in flowers. The enzymes in the TPSf terpene synthase subfamily are responsible for the synthesis of acyclic monoterpenes in Clarkia spp. flowers (Dudareva et al. 1996), reminiscent of the function of TPSb enzymes. However, based on sequence alignments, this subfamily shows greater homology to the diterpene synthase subfamily TPSc. The subfamily TPSg also shows floral expression and enzymes of this subfamily catalyse the formation of only acyclic monoterpenes (Dudareva et al. 2003).

\section{TPSC and TPSe: diterpene synthases}

Unlike volatile terpenes, the process leading to the synthesis of diterpenes requires several enzymatic steps and cyclisation of prenyl diphosphates is carried out in two separate stages by independent enzyme subfamilies. The subfamily TPSc comprises enzymes that catalyse the conversion of GGDP to copalyl diphosphate, a cyclic prenyl diphosphate with a single six-membered ring (Smith et al. 1998). Enzymes in the subfamily TPSe further convert the monocyclic ent-copalyl diphosphate to ent-kaurene, a tricyclic diterpene (Sun and Kamiya 1994). In diterpene biosynthesis, the cyclisation steps are therefore carried out by separate enzymes, whereas in mono- and sesquiterpene synthases (TPSa and TPSb) all cyclisation is catalysed by a single enzyme.

\section{TPSd: gymnosperm terpene synthases}

Whereas the angiosperm terpene synthase subfamilies described so far each have distinct functions, the TPSd group of closely related gymnosperm sequences contains genes coding for mono-, sesqui- and even diterpene synthases (Bohlmann et al. 1997; Schepmann et al. 2001; Martin et al. 2004).

\section{Enzymatic modification of terpenes}

Although many terpenes, such as $\alpha$-pinene and 1,8-cineole, are produced directly by terpene synthases, many other compounds, such as menthol and piperitone, are the result of post-enzymatic modifications of the primary structure. Some of the best described modifications, such as the conversion of (-)limonene to (-)-trans-isopiperitenol and limonene to (-)-transcarveol in mint are carried out by cytochome p450 oxidases (Lupien et al. 1999). NAD-dependent dehydrogenases are also responsible for terpene modification in mint, such as the conversion of isopiperitenol to isopiperitenone (Ringer et al. 2005). Similar processes may be involved in the formation of piperitone and $p$-cymene in Myrtaceae (Fig. 3a). Due to the number of downstream steps contributing to the multitude of components in leaf oil, it is believed that a reasonably modest number of TPS genes can be responsible for complex leaf oils (Schwab 2003; Pichersky et al. 2006).

\section{Non-enzymatic modification of terpenes}

Production of some terpenes is possible without enzymatic catalysis. Monoterpene esters such as linalyl- and geranyl -acetate are thermosensitive and may break down into their components if methods such as steam distillation are used to extract the terpenes from the leaves (Mastelic and Jerkovic 2003). In addition, several monoterpenes that contain polyunsaturated cyclohexane rings can undergo spontaneous conversion into $p$-cymene in the presence of atmospheric oxygen through natural processes such as leaf ageing but also during steam distillation and solid-phase microextraction (Sefidkon et al. 1999; Zabaras and Wyllie 2002).

Among the sesquiterpenes that occur in Myrtaceae, those that have been shown to be direct products of terpene synthases include germacrene-D, bicyclogermacrene, $\beta$-caryophyllene, $\alpha$-humulene, farnesol and farnesene. These structures do not occur as a product of any known spontaneous rearrangement or solvolysis reaction, whereas compounds such as globulol, $\delta$-cadinene and cadinols may be either direct products of terpene synthases, the products of leaf ageing or analysis artefacts (de Kraker et al. 1998; Cornwell et al. 2000a). The majority of the tricyclic structures, such as aromadendrene, alloaromadendrene, globulol and some bicyclic sesquiterpenes, such as the cadinenes, cadinols, eudesmols and cryptomeridiol are likely to be acid solvolysis products of macrocyclic structures (Fig. 3b; Cornwell et al. 2001). Germacrenes A and D, hedycaryol, bicyclogermacrene and $\beta$-germacrenol are all known to form artefacts during steam distillation and in the injector and/or on the column of gas chromatographs 
(Nishimura et al. 1969; Toyota et al. 1996; Cornwell et al. 2001; Lowe et al. 2005; Cornwell et al. 2000b). Similar changes can come about in the leaf during ageing due to exposure to high temperature and ultraviolet radiation (Fadel et al. 1999; Harder and Foss 1999). The sesquiterpenes elemene and elemol have also been shown to be artefacts originating from injector or on-column Cope-rearrangement (Jones and Sutherland 1968; Southwell 1970; de Kraker et al. 1998).

When studying the source of in-vivo leaf oil variation, it is important to consider these rearrangements. Sampling, extraction and analysis methods need to be optimized to reduce the chances of artefact formation, and knowledge of the effect of processes involved needs to be taken into consideration in the interpretation of results.

\section{Terpene secondary metabolites in Australian Myrtaceae}

\section{Non-volatile terpenes of Australian Myrtaceae}

Due to their larger molecular weights and more complex structures, diterpenes, triterpenes and tetraterpenes are significantly less volatile than the monoterpenes and sesquiterpenes. Generally, they are also found in either the water-soluble cell fraction or are in a bound form, making them unavailable for study by the methods used for essential oil analysis.

Triterpenes that are not associated with primary metabolism have been identified from the leaves, wood and bark of several species of Myrtaceae (Mayer 1990; Wang and Fujimoto 1993; Santos et al. 1997; Lee 1998). Of these, pentacyclic triterpenes with oleane, ursane and lupane skeletons such as erythrodiol and

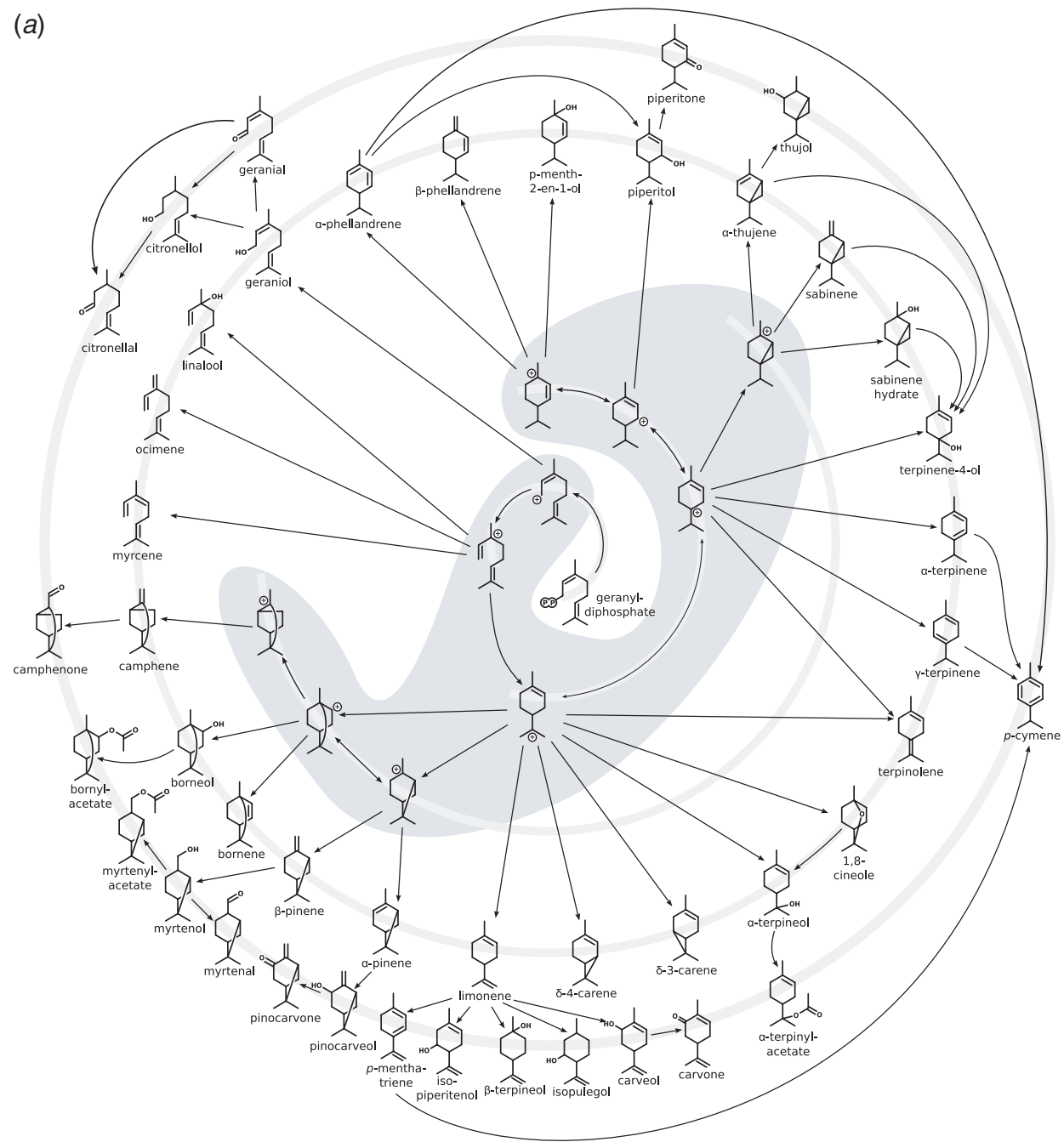

Fig. 3. Reaction mechanisms leading to the formation of $(a)$ the monoterpenes and $(b)$ the sesquiterpenes found in Australian Myrtaceae. Structures on a grey background are intermediates within the terpene synthase catalytic pocket, whereas structures on a white background include the enzyme substrate, enzyme products, and mono- or sesquiterpenes modified by further enzymatic steps. From the centre outward, the circles represent successive levels of structural complexity. The innermost circle represents the acyclic carbocations, the second circle represents monocyclic carbocations and the third circle represents polycyclic carbocations. The fourth circle encompasses all of the mono- or sesquiterpenes that can be direct products of terpene synthase enzymes, whereas the outermost circle represents compounds that can be achieved through further modification of the mono- or sesquiterpene synthase products. 


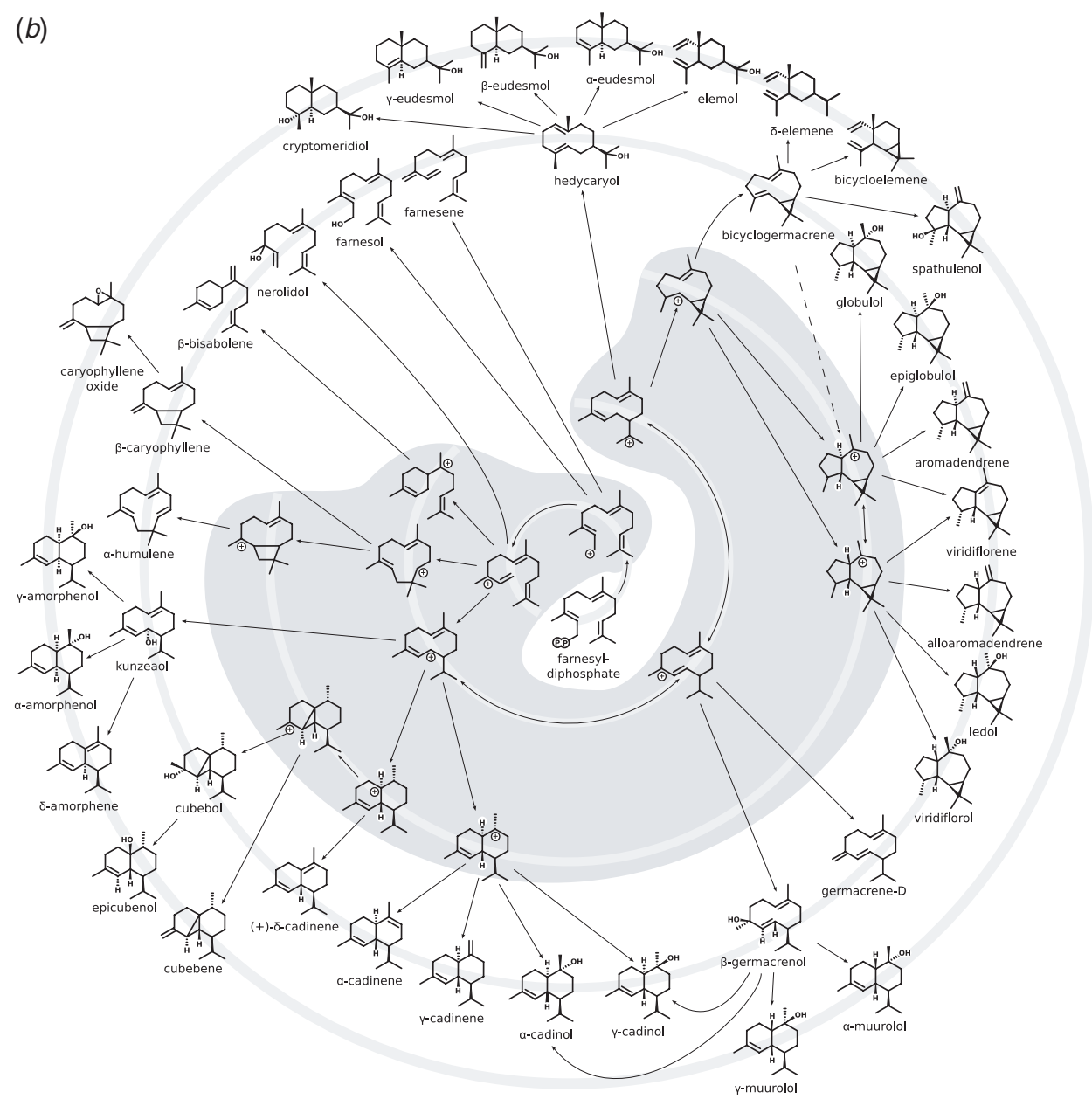

Fig. 3. (continued)

ursolic acid (Fig. 1) predominate. Diterpene secondary metabolites have not been isolated from eucalypts or other Australian Myrtaceae, however, abietic acid has been described from a South American member of the family, Pimenta racemosa var. grissea (Fernandez et al. 2001).

\section{Volatile terpenes of Australian Myrtaceae}

The leaf oils of Australian Myrtaceae may constitute up to $20 \%$ of the wet weight of the leaves (King et al. 2006) and are stored in lysogenic oil glands. In the majority of the Australian Myrtaceae, the leaf oil is dominated by mono- and sesquiterpenes (Brophy and Southwell 2002). They are complex mixtures, often containing over 40 identifiable terpene components of different biosynthetic origins.

Cineole is the dominant monoterpene of Eucalyptus, especially in high oil-yielding species, where it may make up over $90 \%$ of the leaf oil (Boland et al. 1991; Brophy and Southwell 2002). In low oil-yielding eucalypts, however, $\alpha$ pinene is usually the predominant monoterpene (Boland et al. 1991; Brophy and Southwell 2002). Other monoterpenes that are known as major leaf oil constituents in Myrtaceae are piperitone, citronellal, $\alpha$-and $\beta$ - phellandrene, $p$-cymene and terpinen-4-ol.
One of the reasons why monoterpene-type oil profiles are predominant in Myrtaceae, as well as in most aromatic plants, may be that monoterpene synthases use the same plastidic pool of substrates as many of the primary metabolic pathways (biosynthesis of chlorophyll, carotenoids, gibberellin and abscisic acid) (Dubey et al. 2003), whereas the cytosolic pathway that makes sesquiterpenes needs to maintain only one primary metabolic process, the synthesis of sterols (Yoshioka et al. 1999).

Sesquiterpenes generally make up around $10 \%$ of the total leaf oil fraction of Australian Myrtaceae (Boland et al. 1991; Brophy and Southwell 2002), although individuals with leaf oils containing over 70\% sesquiterpenes are known (Dunlop et al. 1999; Asante et al. 2001). The main sesquiterpene hydrocarbons in Australian Myrtaceae are aromadendrene and alloaromadendrene, $\beta$-caryophyllene and bicyclogermacrene and the major terpene alcohols are globulol, spathulenol and eudesmols (Boland et al. 1991; Brophy and Southwell 2002).

\section{Chemical variation of terpenes in Myrtaceae}

The compositions of oils of Australian Myrtaceous species have been well described, with over 400 articles dedicated to 
Table 1. Enzymes capable of catalysing the synthesis of pinene as characterised by terpene synthase assays

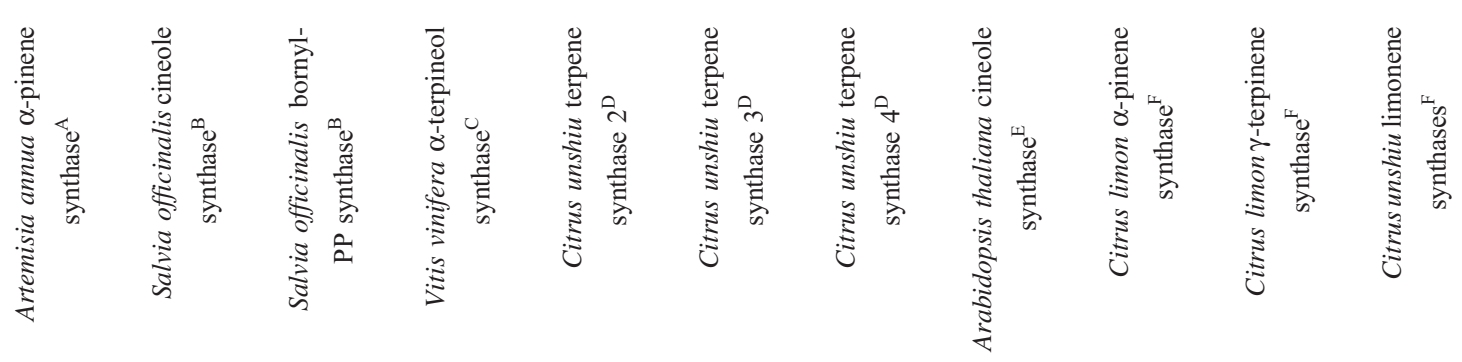

\begin{tabular}{lccccccccccc}
\hline$\alpha$-pinene & $6 \%$ & $6.4 \%$ & $3.4 \%$ & $4.3 \%$ & $9.1 \%$ & $5.8 \%$ & $2.5 \%$ & $1.9 \%$ & $4.1 \%$ & $5.6 \%$ & $0.05 \%$ \\
$\alpha$-pinene (+/-) ratio & $0: 1$ & $6: 1$ & - & - & - & - & - & - & - & - \\
$\beta$-pinene & $94 \%$ & $6.8 \%$ & - & $11.5 \%$ & $6.3 \%$ & $3.7 \%$ & $82.4 \%$ & $7.8 \%$ & $81.4 \%$ & $4.7 \%$ & - \\
$(+) /(-)$ ratio & $0: 1$ & $3: 4$ & - & $3: 1$ & - & - & - & - & - & - \\
$\alpha$-thujene & - & - & - & $2.8 \%$ & $0.1 \%$ & $2.8 \%$ & $1 \%$ & $0.6 \%$ & - & $2.5 \%$ & - \\
$\beta$-myrcene & - & $2.9 \%$ & $2.5 \%$ & $2.5 \%$ & - & - & - & $13.3 \%$ & - & $0.9 \%$ & $0.8 \%$ \\
sabinene & - & $2.6 \%$ & - & $1.3 \%$ & - & - & $4.1 \%$ & $14.5 \%$ & $11 \%$ & $0.4 \%$ & - \\
limonene & - & $1.5 \%$ & $6.5 \%$ & $2.8 \%$ & $0.1 \%$ & $9.3 \%$ & $11.0 \%$ & $4 \%$ & $3.5 \%$ & $9.1 \%$ & $99.2 \%$ \\
terpinolene & - & - & $7 \%$ & $0.7 \%$ & - & - & - & $0.8 \%$ & - & $3.7 \%$ & - \\
camphene & - & - & $10 \%$ & - & - & - & - & - & - & - & - \\
E-ocimene & - & - & - & - & - & - & - & $2.7 \%$ & - & - \\
$\gamma$-terpinene & - & - & - & - & $85.4 \%$ & $78.6 \%$ & $1 \%$ & - & $0.05 \%$ & $71.4 \%$ & - \\
bornyl-PP & - & - & $75 \%$ & - & - & - & - & - & - & - & - \\
1,8 -cineole & - & $79 \%$ & - & $11.8 \%$ & - & - & - & $52 \%$ & - & - & - \\
sabinene-hydrate & - & - & - & $9.5 \%$ & - & - & - & - & - & - \\
$\alpha$-terpineol & - & $2 \%$ & - & $52 \%$ & - & - & - & $2.4 \%$ & - & - \\
\hline
\end{tabular}

${ }^{\mathrm{A}}\left(\mathrm{Lu}\right.$ et al. 2002); ${ }^{\mathrm{B}}$ (Wise et al. 1998); ${ }^{\mathrm{C}}$ (Martin and Bohlmann, 2004); ${ }^{\mathrm{D}}$ (Shimada et al. 2004); ${ }^{\mathrm{E}}$ (Chen et al. 2004); ${ }^{\mathrm{F}}$ (Lücker et al. 2002).

cataloguing the differences among and within individuals, populations and species (Boland et al. 1991; Brophy and Southwell 2002). In particular, a large number of chemotypes have been identified. Chemotypes are defined as readily identifiable, discontinuous quantitative differences in chemical composition between individuals within a population that cannot be distinguished from each other by morphometric properties (Penfold and Willis 1953). We will apply the term in a less strict sense to include all characteristic discontinuous traits within a class of plant secondary metabolites, regardless of taxonomic or geographic divisions.

The chemical differences that define an essential oil or terpene chemotype should be characteristic of constitutive terpene production in adult plants. Although differences in induced or seasonally changing chemistries are also likely to occur, they are far from easy to assess. Emphasis should be placed on the in vivo chemical profiles of individual plants present in natural communities, as this is most likely to yield information on the ecological processes leading to the evolution of the chemical variation observed.

\section{The complexity of chemical variation}

\section{Variation in terpene concentration}

Variation in the total concentration of terpenes is the most important type of variation relevant to the essential oil industry. Total terpene concentration is influenced by environmental and genetic factors and the processes leading to an increase or decrease in foliar terpene concentration may arise at several stages of the metabolic pathway. Changes in the availability of enzymes of terpene biosynthesis affect all oil components. As discussed previously, this can result from changes in the regulation of the DXP and MVA pathways.

In species where the leaf oil is dominated by a single compound (e.g. $80 \%$ cineole in Eucalyptus polybractea) (Boland et al. 1991), loss of activity of the synthase responsible can cause not only the ratio of that one component to change, but will also significantly decrease the oil concentration if no other synthase is present that can utilise the same substrate at the same rate. Differences in the abundance of the substrate required for the synthesis of the dominant compound (in this case GDP) can have the same effect, as long as the conversion of the prenyl diphosphate into terpenes is limited only by substrate availability.

\section{Variation in terpene profile}

Leaf oil profiles are characterised by the presence or absence of individual components, irrespective of overall terpene content or the ratios of the components to each other. Chemotypic variants that are defined by the appearance of novel compounds in the leaf oil, for example nerolidol in Chemotype 2 of Leptospermum novae-anglicae (Brophy et al. 1999a) can be considered oil profile chemotypes. This type of variation can either be caused by a change in the product profile of a terpene synthase, or a change in the substrate specificity of a terpene-modifying enzyme.

This is most likely the case in Eucalyptus radiata, where the presence or absence of piperitone is the major difference between 
two of the six known chemotypes (Johnstone 1984; Boland et al. 1991). The ketone group in compounds such as piperitone is unlikely to result from reactions that can be directly catalysed by terpene synthases. Therefore, separate enzymes must be involved in the conversion of a terpene hydrocarbon ( $\alpha$-phellandrene) or a terpene alcohol (piperitol) into a ketone (piperitone). In the case of piperitone, this scheme is supported by the co-occurrence of $\alpha$ phellandrene and piperitone in E. radiata chemotype 2 (Boland et al. 1991), and the presence of an intermediate chemotype characterised by high piperitol content in mosaic $E$. radiata individuals (Penfold and Morrison 1937). The conversion of $\alpha$-phellandrene to piperitol is most likely catalysed by a $\mathrm{p} 450$ monoxygenase, analogous to the conversion of limonene to (-)-trans-carveol in mint (Lupien et al. 1999). The conversion of piperitol to piperitone, however, is most likely aided by an NAD-dependent dehydrogenase, similar to the action of isopiperitenol dehydrogenase in mint (Ringer et al. 2005) (Fig. 3a). Both enzymes are substrate specific and genetic change leading to a shift in the preferred substrate at any of these steps would lead to the observed chemotypic changes in the oil profile.

Variation in terpene-FPC adducts in Eucalyptus globulus and Eucalyptus melliodora (Moore et al. 2004) is likely to follow a similar mechanism, if the presence or absence of macrocarpals is determined by the function of enzymes catalysing FPC-terpene additions. As macrocarpals, euglobals and other terpene-FPC adducts do not form a part of the leaf oil, such biochemical processes may also have a direct effect on the leaf oil profile by removing individual components from the pool of volatile terpenes.

\section{Variation in terpene composition}

We define terpene composition as the proportion of the individual compounds present. As terpene synthases often have overlapping product profiles, most of the variation in these genes can be expected to affect the composition of the terpenes as opposed to the profile. In certain cases, the ratio of entire chemical classes such as sesquiterpenes and monoterpenes can vary between chemotypes (e.g. Eucalyptus camphora Chemotypes 2 and 3 and Eucalyptus camaldulensis Chemotypes 1 and 2) (Boland et al. 1991), and this may be influenced by the IDP:DMADP ratio as determined by the activity and expression of IDPI. However, more often the chemotypes are defined by a significant shift in the relative concentrations of more similar compounds, such as cineole and $\alpha$-pinene in Leptospermum polygalifolium (Brophy et al. $2000 a$ ). Compositional chemotypes are most likely the results of changes in a single element of the biosynthetic pathway, affecting the relative concentrations of only a few of the final products. This can happen indirectly through differential regulation of the given metabolic step, or directly through the loss or alteration of function of an enzyme. This has been reported from maize, where changes in the sequence of one sesquiterpene synthase can account for the major differences between the volatiles emitted by two cultivars (Köllner et al. 2004).

One approach in identifying the actions of individual enzymes in the oil profiles is by correlating the concentrations of individual oil components in a large number of individuals.
For example, there are clear correlations between $\alpha$ - and $\beta$-pinene in E. globulus and E. nitens, and $\alpha-, \beta$ - and $\gamma$-eudesmol in E. camphora (Boland et al. 1991; Li et al. 1996). Unfortunately these patterns are not always apparent because of the low number of known chemical variants from any species, overlapping enzyme product profiles and postenzymatic modification of terpenes. Ultimately, these questions can only be answered through the isolation and characterisation of the individual enzymes active in the oil glands.

\section{Molecular mechanisms of variation}

Recall that variation in leaf oils may be brought about by sequence variation of multiple genes involved with the terpene biosynthesis pathway. Terpene synthases occur in tandem gene duplicates in the Arabidopsis thaliana genome (Aubourg et al. 2002), similar to other genes involved with secondary metabolism (Kliebenstein et al. 2001). In other species, terpene synthases closely related to primary metabolism pathways have also arisen from gene duplication (Qi et al. 2004). Such duplication events provide ample opportunity for novel functions to arise through genetic mutation, without it being detrimental to the organism (Benderoth et al. 2006).

\section{Variation in the exons}

Among the different types of genetic mutations, those occurring in the exons are the most likely to have a direct effect on protein function. Indels can change the reading frame creating premature stop codons. In terpene synthases, this is almost certain to cause the protein to lose function, as the active site residues are predominantly at the C-terminal domain (Whittington et al. 2002). Non-frame-shifting mutations of this kind will also disrupt the tertiary structure of the protein. Single base substitutions, however, have proven to give the most information on the relationship between enzyme structure and function. In maize, as little as two amino acid substitutions can lead to either inactivity or a change in the composition of the products of a sesquiterpene synthase (Köllner et al. 2004). Similarly in peppermint, a single SNP has been shown to be responsible for the conversion of a farnesene synthase to cismuuroladiene synthase (Prosser et al. 2006).

As exon mutations in terpene synthases have already been shown to be responsible for chemotypes in other species, they are the most likely candidates for the phenomenon in Myrtaceae. Depending on the extent to which gene function is affected, such changes may result in changes in the terpene composition, profile, and if upstream pathway elements are involved, even in terpene concentration.

\section{Variation in the introns}

Although not coding directly for amino acids, motifs in the introns called exon splicing enhancers (ESE) determine the maturation of mRNA, which is crucial for the correct translation of the protein code. Changes affecting ESEs can be responsible for alternative splicing patterns, which can have an effect similar to that of indels in the exon. Even if the failure to 
excise an intron does not shift the frame of translation, the change in the length of the protein makes correct folding unlikely. This results in a pseudogene with correct and specific expression but no resultant phenotype.

Single nucleotide polymorphisms leading to differences in splicing have been documented as the cause of several medical conditions in humans (e.g. Denson et al. 2006). In plants, similar sequence variation has been reported in the CCR gene family of the lignin biosynthesis pathway in E. nitens, where SNPs in ESE motifs resulted in pseudogenes upon transcription (Thumma et al. 2005).

In maize, a chemically simple system where the mixture of emitted volatiles is essentially determined by a single gene, a combination of single nucleotide polymorphisms and a translation frame shift (similar to that resulting from differential splicing) between two cultivars is sufficient to bring about chemotypic differences (Köllner et al. 2004).

\section{Variation in organelle targeting}

All terpene synthases are coded in the nuclear genome, and those active in the plastids need to be transported following translation. Accordingly, chloroplast targeting peptides or cTPs can be found at the C-terminal of all hemi-, mono- and diterpene synthases (Wise et al. 1998; Miller et al. 2001; Nakagiri et al. 2005). Cleavage of the signal peptide occurs in the stroma (Bruce 2000), and it has been shown in several heterogously expressed plastidic terpene synthase genes, that enzyme activity is only achieved once the cTP region has been cleaved (Williams et al. 1998; Bohlmann et al. 1999). Thus, the cTP not only directs the enzyme to the compartment where its substrate is available, but also ensures that the terpene synthase only becomes active in its designated cellular compartment. cTP mutations have been shown to lead to significant decrease of the phenotype linked to the expression of a protein, even though expression and active site regions were not affected (Lawrence and Kindle 1997; Kindle 1998; Kindle and Lawrence 1998).

\section{Variation in regulatory elements}

The observed chemical phenotype depends on the function of the enzymes, and also on the way in which they are expressed. Changes to either ontogenetic, organ-specific or response-specific regulatory elements have the potential to significantly alter the oil profile. For example, one of the epi-aristolochene terpene synthases of Capsicum annuum showed increased expression on UV treatment (Back et al. 1998), another on exposure of the fruits to cellulase enzymes (Cano-Camacho et al. 1997) and a third shows increased levels of expression upon exposure to Phytophthora capsaici (Zavala-Paramo et al. 2000). The major difference between these was not in the functional domains of the genes, but in the promoter regions.

It is possible that chemically well defined phenotypic differences may not correlate with changes in any of the genes involved in the terpene biosynthesis pathway directly. In such cases, analysis of the promoter regions, and ultimately, analysis of the expression levels of terpene biosynthesis genes via quantitative PCR may be necessary.

\section{Variation of leaf oil chemistry within the individual}

\section{Chemical variation reflecting environmental effects}

As terpene biosynthesis is closely linked with processes in primary metabolism responsible for the maintenance of photosynthesis and the dynamics of biological membranes, it is not surprising to find that the environmental conditions that affect terpene content and composition most strongly are temperature and light. In Quercus ilex which does not store terpenes, steady-state monoterpene emissions have been shown to increase by an order of magnitude in conditions of high light intensity and high temperature (Staudt et al. 2003). Although terpene emission is essentially a passive physical process, its rate is also dependent on the amount of terpenes being produced.

Although the evaporation of volatiles increases with temperature, the increased rate of monoterpene production to keep pace depends on a corresponding change in enzyme regulation. The increased concentration of monoterpenes in the leaf drastically increases the thermotolerance of photosynthesis up to $45^{\circ} \mathrm{C}$ (Loreto et al. 1998), suggesting that this is a physiologically directed process. An increase of leaf temperature has also been shown to increase terpene emissions in several species of Eucalyptus (Guenther et al. 1991; He et al. 2000b).

\section{Chemical variation in response to biotic interactions}

Mechanical wounding, pathogen recognition, herbivory and plant-to-plant signalling can all trigger changes in the plant leading to large changes in metabolism and allocation of secondary metabolites. Significant changes in terpene biosynthesis have been observed in Pinus ponderosa where an altered chemotype was still observable four months after herbivory (Barnola et al. 1994). Similar changes related to herbivory have been reported from maize leaves and roots (Degenhardt et al. 2003; Rasmann et al. 2005), and also from Gossypium spp. upon challenge by pathogenic bacteria (Davilahuerta et al. 1995). Similar changes, however, have not been reported from Myrtaceae, but that does not necessarily mean that the phenomenon does not occur. Large-scale defoliation events by insects and mammalian herbivores are occasionally observed in Eucalyptus forests (Lowman and Heatwole 1992; Di Stefano 2005; Mansfield et al. 2006), but due to the sporadic nature of these events, they are not suitable for thorough and repeatable analysis of changes in foliar chemistry.

\section{Genetically controlled chemical variation within individuals}

\section{Ontogenetic differences in leaf chemistry}

Organ ontogeny generally mirrors seasonal change. Changes due to plant age, leaf age and seasonal change are difficult to separate from each other and a different range of compounds is present at different stages of both plant and organ development. Most within-plant variation in chemistry in Eucalyptus can be attributed to leaf age rather than seasonal effects (Simmons and Parsons 1987), as the separate biosynthetic enzymes contributing to the final composition of the essential oils appear to be expressed at different times (McConkey et al. 2000; Southwell and Russell 2002; Davis et al. 2005). Non-enzymatic rearrangements can also 
take place within the oil glands (e.g. conversion of sabinene hydrate to terpinen-4-ol in M. alternifolia) (Southwell and Stiff 1989; Russell and Southwell 2002).

Despite the importance of individual leaf age in determining chemical composition, the age of the plant and individual branches may have even more marked effects on the chemical profile (Suomela and Ayres 1994; Kearsley and Whitham 1998). Although many species of Eucalyptus show heteroblasty and related differences in epicuticular wax (Brennan et al. 2001), corresponding differences in terpene composition have only been shown in a few e.g. E. delegatensis (Boland et al. 1982; Weston 1984; Boland et al. 1991). In most species studied, however, there is no correlation between heteroblasty and terpene chemistry (Li et al. 1996).

In Leptospermum petersonii, the leaves of seedlings up to the fifth node have a remarkably different leaf oil composition than leaves from the sixth node up (Brophy et al. $2000 \mathrm{~b}$ ). The oils of leaves on the fifth and sixth nodes had no common components, and were more different from each other than the oil from mature leaves of L. petersonii and L. liversidgei. Such a significant shift in leaf oil composition suggests a strong ontogenetic control of multiple steps of terpene biosynthesis, and suggests that genetic variation in the regulatory elements responsible may account for some of the chemotypes occurring in natural populations.

\section{Chemical mosaicism}

In Eucalyptus, striking terpene variation that cannot be explained by environmental or ontogenetic differences has been observed within single trees. These individuals are thought to be genetic mosaics. This has only been observed in a limited number of cases. In a seedling of E. radiata, one branch yielded oil containing $50 \%$ piperitone, whereas the other yielded oil containing only $18 \%$ piperitone, with a considerable proportion of piperitol (Penfold and Morrison 1937). Later, Edwards et al. (1990) found that the leaves on different branches of naturally occurring $E$. melliodora contained vastly different concentrations of cineole. Both of these examples can be explained by single meristematic mutations in genes involved with terpene biosynthesis, which persist in the parts of the plant developing from the affected cells.

Somatic mutation is the likely cause of phenotypically expressed mosaicism in long-lived plants such as trees (Edwards et al. 1993). Mosaics may provide an ideal system for the analysis of molecular changes leading to ecologically significant changes in chemotype. As the change may be in any of several regulatory elements or biosynthesis genes, identifying the exact mutation within the genome and characterising its phenotypic effects is still a formidable task.

\section{Variation of leaf oil chemistries between individuals}

\section{Chemotypes can indicate taxonomic separation}

Related species often show similar terpene chemistries (Doran et al. 1995; Perry et al. 1997; de Carvalho and Roque 2004), however, similar sets of compounds can appear in the oil profile of taxonomically unrelated groups. In some examples in Eucalyptus, the presence of a unique compound or group of compounds may be characteristic of well defined taxonomic units, such as piperitol and piperitone in the series Piperitae (Bignell et al. 1998) or in the subseries Strictinae, series Obliquae (Lassak and Southwell 1982). Presence of these chemicals indicates the presence of specific biosynthetic enzymes, and therefore may have taxonomic relevance.

The processes involved in reaching the final chemotype is complex, and in natural populations, the action of individual alleles may be difficult to discern as the change they bring about may be hidden by other factors acting on the same chemical component. The interaction of genetic components determining leaf chemistry is more easily detected in the case of hybrids. Natural hybridisation affecting the chemical composition of leaf oil has been observed between Eucalyptus crenulata and Eucalyptus ovata (Simmons and Parsons 1976) and an intermediate chemotype independent of morphological characteristics of the hybrids was observed. Synthetic hybrids show a similar pattern (Shepherd et al. 1999; Dungey et al. 2000).

\section{Chemotypes can reflect geographic separation}

Chemical differences that are consistent and characteristic of geographically separate populations or provenances have been well documented in several species of Eucalyptus, Melaleuca, and Leptospermum (Homer et al. 2000; Lee et al. 2002). For example, $L$. polygalifolium has seven chemically and morphologically characterised subspecies (Brophy et al. $2000 a$ ). The oil profiles vary in both profile and composition, and oil yields vary from $0.1 \%$ to $3 \%$ of fresh weight between the subspecies.

Variation in leaf chemistry occurs not only among discontinuous populations, but in some cases may be geographically structured within continuous ranges of distribution. Latitudinal chemotypic boundaries occur in at least two Australian species with distributions that span climatic boundaries. Backhousia citriodora has two major chemotypes over its mostly continuous range, with a discrete boundary between the citral and citronellal dominated chemotypes found at $\sim 25^{\circ} \mathrm{S}$ (Doran et al. 2001). Melaleuca quinquenervia is also characterised by two main chemotypes: chemotype 1 is dominated by nerolidol and chemotype 2 by 1,8-cineole. Chemotype 2 can be found throughout its range, whereas chemotype 1 only occurs south of Latitude $25^{\circ} \mathrm{S}$ (Ireland et al. 2002).

\section{Co-occurring chemotypes}

The classic cases of distinct chemotypes are found side by side within natural and cultivated populations, and the segregation of traits in crosses show Mendelian patterns of inheritance. Such chemotypes are best known from Thymus vulgaris (Linhart and Thompson 1995) and Pinus pinaster (Plomion et al. 1996). Among the Myrtaceae, chemotypes coexisting in natural populations have also been described from many species of eucalypts (e.g. Penfold and Morrison 1927; Brophy et al. 1999b), but are best known from M. alternifolia. Five out of the eleven populations of M. alternifolia, studied by Butcher $\mathrm{et}$ al. (1994) have more than one chemotype co-occurring. Most of these chemical forms can be considered to represent the appearance of new traits following speciation, and are indeed 
unique to this species. However, the terpinolene-dominated chemotypes (C and D) in the north-west of M. alternifolia's range of distribution show a strong similarity to the leaf chemistry of M Melaleuca trichostachya (Butcher et al. 1994; Homer et al. 2000). Although chemical similarity may simply indicate common ancestry of the two species, Butcher et al. (1994) proposed that chemotypes C and D may result from introgression. This is supported by the fact that $M$. alternifolia is otherwise characterised by terpinen-4-ol dominated leaf oil (Penfold 1925; Jones 1937; Southwell and Stiff 1990) and the high terpinolene chemotypes only occur in the contact zone between the two species. Similar processes may also have brought about the citronellol-dominated chemotype of the otherwise limonene and $\alpha$-pinene-dominated Chamelaucium uncinatum (Egerton-Warburton et al. 1998a) at the northern extreme of its range, as it readily hybridises with other species and even genera within the Chamelaucium alliance, and possible past hybridization is also supported by morphological traits (Egerton-Warburton et al. 1998b).

These examples suggest that chemotypes may not necessarily be characteristic of individual species. Both common ancestry and gene flow between species can be responsible for similar chemotypes appearing in different species, and in both of these cases it can be assumed that this would be the result of similar enzymes being present in the biosynthetic pathways.

\section{Conclusions}

The wealth of published information on terpene diversity in Eucalyptus and other Myrtaceae in Australia shows that the family possibly contains some of the most variable genera regarding terpene secondary metabolites. Research into the biochemical pathways leading to the formation of foliar volatiles has made significant headway in industrially significant species around the world; however Myrtaceae in Australia and elsewhere is surprisingly under-represented. In Myrtaceae, chemical variability appears to be a common and significant characteristic of individual species, therefore uncovering the origin of chemical variation has both ecological and phylogenetic significance. In revegetation and land-restoration schemes, such findings can help in selecting not only the right species for a site, but also the right chemical forms corresponding to the niches inhabited by the fauna of the area. The essential oil industry can make use of knowledge of genetic markers of oil composition in screening for individuals of optimal oil yield and quality in natural populations and trials. The use of DNA-based techniques means that screening could be carried out before planting and the maturation of the foliar chemotype, and that subsequent generations can be further screened to maintain the optimal characteristics in spite of open-pollination. The tools are now available to isolate and characterise the genes of interest in Myrtaceae, and to link chemical variation to gene sequence variation. Undoubtedly, the advances provided by sequencing projects involving the Eucalyptus genome will bring our understanding of that genus to a new level. However, further work on the biochemical and population genetic aspects of foliar terpene variation needs to be carried out in order for us to be able to fully utilise this upcoming resource.

\section{Acknowledgements}

Comments by Rose Andrew, Erich Lassak and anonymous reviewers improved this manuscript significantly. We are grateful to Charles Cornwell, Erich Lassak, Joe Brophy, Noel Davies, Jonathan Gershenzon and Jörg Degenhardt for enjoyable discussions of terpene metabolism. This work was supported by a grant from the Australian Research Council to William J. Foley and by Andras Keszei who was supported by an International Postgraduate Research Award from the Australian National University.

\section{References}

Allen BE, Banthorpe DV (1981) Partial purification and properties of prenyltransferase from Pisum sativum. Phytochemistry 20, 35-40. doi: 10.1016/0031-9422(81)85214-4

Alves MDC, Medeiros S, Innecco R, Torres SB (2004) Allelopathy of plant volatile extracts on seed germination and radicle length of lettuce. Pesquisa Agropecuaria Brasileira 39, 1083-1086.

Anon. (2004) Opinion on Tea Tree Oil. Scientific Committee on Consumer Products. Opinion Number SCCP/08438/04. European Commission Health \& Consumer Protection Directorate-General, Brussels.

Asante KS, Brophy JJ, Doran JC, Goldsack RJ, Hibbert DB, Larmour JS (2001) A comparative study of the seedling leaf oils of the spotted gums: species of the Corymbia (Myrtaceae) Section Politaria. Australian Journal of Botany 49, 55-66. doi: 10.1071/BT00006

Aubourg S, Lecharny A, Bohlmann J (2002) Genomic analysis of the terpenoid synthase (AtTPS) gene family of Arabidopsis thaliana. Molecular Genetics and Genomics 267, 730-745. doi: 10.1007/s00438-002-0709-y

Back KW, He SL, Kim KU, Shin DH (1998) Cloning and bacterial expression of sesquiterpene cyclase a key branch point enzyme for the synthesis of sesquiterpenoid phytoalexin capsidiol in UV-challenged leaves of Capsicum annuum. Plant \& Cell Physiology 39, 899-904.

Barnola LF, Hasegawa M, Cedeno A (1994) Monoterpene and sesquiterpene variation in Pinus caribaea needles and its relationship to Atta laevigata herbivory. Biochemical Systematics and Ecology 22, 437-445. doi: 10.1016/0305-1978(94)90039-6

Bell SJ, Barton AFM, Stocker LJ (2001) Agriculture for health and profit in Western Australia: The Western Oil Mallee Project. Ecosystem Health 7, 116-121. doi: 10.1046/j.1526-0992.2001.007002116.x

Benderoth M, Textor S, Windsor AJ, Mitchell-Olds T, Gershenzon J, Kroymann J (2006) Positive selection driving diversification in plant secondary metabolism. Proceedings of the National Academy of Sciences, SA 103, 9118-9123. doi: 10.1073/pnas.0601738103

Bignell CM, Dunlop PJ, Brophy JJ (1998) Volatile leaf oils of some southwestern and southern Australian species of the genus Eucalyptus (Series 1). Part XIX. Flavour and Fragrance Journal 13, 131-139. doi: 10.1002/(SICI)1099-1026(199803/04)13:2<131::AID-FFJ710>3.0. $\mathrm{CO} ; 2-\mathrm{X}$

Bohlmann J, Steele CL, Croteau RB (1997) Monoterpene synthases from grand fir (Abies grandis). cDNA isolation characterization and functional expression of myrcene synthase (-)-(4S)-limonene synthase and (-) (1S 5S)-pinene synthase. Journal of Biological Chemistry 272, 21784-21792. doi: 10.1074/jbc.272.35.21784

Bohlmann J, Crock J, Jetter R, Croteau RB (1998a) Terpenoid-based defenses in conifers: cDNA cloning characterization and functional expression of wound-inducible (E)-alpha-bisabolene synthase from grand fir (Abies grandis). Proceedings of the National Academy of Sciences, USA 95, 6756-6761. doi: 10.1073/pnas.95.12.6756

Bohlmann J, Meyer-Gauen G, Croteau RB (1998b) Plant terpenoid synthases: molecular biology and phylogenetic analysis. Proceedings of the National Academy of Sciences, USA 95, 4126-4133. doi: 10.1073 /pnas.95.8.4126 
Bohlmann J, Phillips M, Ramachandiran V, Katoh S, Croteau RB (1999) cDNA cloning characterization and functional expression of four new monoterpene synthase members of the Tpsd gene family from grand fir (Abies grandis). Archives of Biochemistry and Biophysics 368, 232-243. doi: 10.1006/abbi.1999.1332

Boland DJ, Brophy JJ, Flynn TM, Lassak EV (1982) Volatile leaf oils of Eucalyptus delegatensis seedlings. Phytochemistry 21, 2467-2469. doi: 10.1016/0031-9422(82)85242-4

Boland DJ, Brophy JJ, House APN (1991) 'Eucalyptus leaf oils.' (Inkata Press: Sydney)

Bouvier F, Suire C, d'Harlingue A, Backhaus RA, Camara B (2000) Molecular cloning of geranyl diphosphate synthase and compartmentation of monoterpene synthesis in plant cells. The Plant Journal 24, 241-252. doi: 10.1046/j.1365-313x.2000.00875.x

Brennan EB, Weinbaum SA, Rosenheim JA, Karban R (2001) Heteroblasty in Eucalyptus globulus (Myricales: Myrtaceae) affects ovipositonal and settling preferences of Ctenarytaina eucalypti and C. spatulata (Homoptera: Psyllidae). Environmental Entomology 30, 1144-1149.

Brophy JJ, Southwell IA (2002) Eucalyptus chemistry. In 'Eucalyptus: the genus Eucalyptus'. (Ed. JJW Coppen) pp. 102-160. (Taylor \& Francis: London)

Brophy JJ, Clarkson JR, Craven LA, Forrester RI (1994) The essential oils of Australian members of the genus Asteromyrtus (Myrtaceae). Biochemical Systematics and Ecology 22, 409-417. doi: 10.1016/0305-1978(94)90032-9

Brophy JJ, Goldsack RJ, Bean AR, Forster PI, Lepschi BJ (1999a) Leaf essential oils of the genus Leptospermum (Myrtaceae) in eastern Australia Part 4. Leptospermum deanei and allies. Flavour and Fragrance Journal 14, 92-97. doi: 10.1002/(SICI)1099-1026(199903/04)14:2<92::AID-FFJ787>3.0. $\mathrm{CO} ; 2-\mathrm{D}$

Brophy JJ, Goldsack RJ, Bean AR, Forster PI, Lepschi BJ (1999b) Leaf essential oils of the genus Leptospermum (Myrtaceae) in eastern Australia. Part 5. Leptospermum continentale and allies. Flavour and Fragrance Journal 14, 98-104. doi: 10.1002/(SICI)1099-1026(199903/04)14:2<98::AID-FFJ797>3.0. $\mathrm{CO} ; 2-\mathrm{V}$

Brophy JJ, Goldsack RJ, Bean AR, Forster PI, Lepschi BJ (2000a) Leaf essential oils of the genus Leptospermum (Myrtaceae) in eastern Australia. Part 6. Leptospermum polygalifolium and allies. Flavour and Fragrance Journal 15, 271-277.

doi: 10.1002/1099-1026(200007/08)15:4<271::AID-FFJ910>3.0.CO; 2-E

Brophy JJ, Goldsack RJ, Punruckvong A, Bean AR, Forster PI, Lepschi BJ, Doran JC, Rozefelds AC (2000b) Leaf essential oils of the genus Leptospermum (Myrtaceae) in eastern Australia. Part 7. Leptospermum petersonii, L. liversidgei and allies. Flavour and Fragrance Journal 15, 342-351.

doi: 10.1002/1099-1026(200009/10)15:5<342::AID-FFJ924>3.0.CO;2-V

Bruce BD (2000) Chloroplast transit peptides: structure function and evolution. Trends in Cell Biology 10, 440-447. doi: 10.1016/S0962-8924(00)01833-X

Butcher PA, Doran JC, Slee MU (1994) Intraspecific variation in leaf oils of Melaleuca alternifolia (Myrtaceae). Biochemical Systematics and Ecology 22, 419-430. doi: 10.1016/0305-1978(94)90033-7

Cano-Camacho H, Lopez-Romero E, Lozoya-Gloria E (1997) Partial purification and characterization of an elicitor stimulated sesquiterpene cyclase from chili pepper (Capsicum annuum L.) fruits. Plant Science 124, 23-31.

doi: 10.1016/S0168-9452(97)04598-6

Chen F, Ro DK, Petri J, Gershenzon J, Bohlmann J, Pichersky E, Tholl D (2004) Characterization of a root-specific Arabidopsis terpene synthase responsible for the formation of the volatile monoterpene 1,8-cineole. Plant Physiology 135, 1956-1966. doi: $10.1104 / p p .104 .044388$
Copolovici LO, Filella I, Llusia J, Niinemets U, Penuelas J (2005) The capacity for thermal protection of photosynthetic electron transport varies for different monoterpenes in Quercus ilex. Plant Physiology 139, 485-496. doi: 10.1104/pp.105.065995

Cornwell CP, Reddy N, Leach DN, Wyllie SG (2000a) Hydrolysis of hedycaryol: the origin of the eudesmols in the Myrtaceae. Flavour and Fragrance Journal 15, 421-431.

doi: 10.1002/1099-1026(200011/12)15:6<421::AID-FFJ933>3.0.CO; $2-\mathrm{G}$

Cornwell CP, Reddy N, Leach DN, Wyllie SG (2000b) Origin of (+)-deltacadinene and the cubenols in the essential oils of the Myrtaceae. Flavour and Fragrance Journal 15, 352-361.

doi: 10.1002/1099-1026(200009/10)15:5<352::AID-FFJ925>3.0.CO; $2-\mathrm{R}$

Cornwell CP, Reddy N, Leach DN, Wyllie SG (2001) Germacradienols in the essential oils of the Myrtaceae. Flavour and Fragrance Journal 16, 263-273. doi: 10.1002/ffj.991

Davilahuerta G, Hamada H, Davis GD, Stipanovic RD, Adams CM, Essenberg M (1995) Cadinane-type sesquiterpenes induced in Gossypium cotyledons by bacterial inoculation. Phytochemistry 39, 531-536. doi: 10.1016/0031-9422(94)00958-V

Davis EM, Ringer KL, McConkey ME, Croteau RB (2005) Monoterpene metabolism cloning expression and characterization of menthone reductases from peppermint. Plant Physiology 137, 873-881. doi: $10.1104 /$ pp. 104.053306

de Carvalho LR, Roque NF (2004) Correlations between primary and secondary metabolites in Ceramiales (Rhodophyta). Biochemical Systematics and Ecology 32, 337-342. doi: 10.1016/S0305-1978(03)00154-6

Degenhardt J, Gershenzon J, Baldwin IT, Kessler A (2003) Attracting friends to feast on foes: engineering terpene emission to make crop plants more attractive to herbivore enemies. Current Opinion in Biotechnology 14, 169-176. doi: 10.1016/S0958-1669(03)00025-9

de Kraker JW, Franssen MCR, de Groot A, Konig WA, Bouwmeester HJ (1998) (+)-Germacrene a biosynthesis the committed step in the biosynthesis of bitter sesquiterpene lactones in chicory. Plant Physiology 117, 1381-1392. doi: 10.1104/pp.117.4.1381

de Meijer EPM, Hammond KM (2005) The inheritance of chemical phenotype in Cannabis sativa L. (II): Cannabigerol predominant plants. Euphytica 145, 189-198. doi: $10.1007 / \mathrm{s} 10681-005-1164-8$

Denson J, Xi Z, Wu Y, Yang W, Neale G, Zhang J (2006) Screening for inter-individual splicing differences in human GSTM4 and the discovery of a single nucleotide substitution related to the tandem skipping of two exons. Gene 379, 148-155. doi: 10.1016/j.gene.2006.05.012

Di Stefano J (2005) Mammalian browsing damage in the Mt. Cole State Forest southeastern Australia: analysis of browsing patterns spatial relationships and browse selection. New Forests 29, 43-61. doi: 10.1007/s11056-004-6767-8

Doran JC, Williams ER, Brophy JJ (1995) Patterns of variation in the seedling leaf oils of Eucalyptus urophylla E. pellita and E. scias. Australian Journal of Botany 43, 327-336. doi: 10.1071/BT9950327

Doran JC, Brophy JJ, Lassak EV, House APN (2001) Backhousia citriodora F.Muell: rediscovery and chemical characterization of the L-citronellal form and aspects of its breeding system. Flavour and Fragrance Journal 16, 325-328. doi: 10.1002/ffj. 1003

Dubey VS, Ritu Bhalla R, Luthra R (2003) An overview of the nonmevalonate pathway for terpenoid biosynthesis in plants. Journal of Biosciences 28, 637-646. doi: 10.1007/BF02703339 
Dudareva N, Cseke L, Blanc VM, Pichersky E (1996) Evolution of floral scent in Clarkia: novel patterns of S-linalool synthase gene expression in the C. breweri flower. The Plant Cell 8, 1137-1148. doi: $10.2307 / 3870357$

Dudareva N, Martin D, Kish CM, Kolosova N, Gorenstein N, Faldt J, Miller B, Bohlmann J (2003) (E)-beta-ocimene and myrcene synthase genes of floral scent biosynthesis in snapdragon: function and expression of three terpene synthase genes of a new terpene synthase subfamily. The Plant Cell 15, 1227-1241. doi: $10.1105 / \mathrm{tpc} .011015$

Dungey HS, Potts BM, Whitham TG, Li HF (2000) Plant genetics affects arthropod community richness and composition: Evidence from a synthetic eucalypt hybrid population. Evolution 54, 1938-1946.

Dunlop PJ, Bignell CM, Brooker MIH, Brophy JJ, Hibbert DB (1999) Use of gas chromatograms of essential leaf oils to compare eight taxa of genus Angophora (Myrtaceae): possible relationships to the genus Eucalyptus. Biochemical Systematics and Ecology 27, 815-830. doi: 10.1016/S0305-1978(99)00022-8

Edwards PB, Wanjura WJ, Brown WV, Dearn JM (1990) Mosaic resistance in plants. Nature 347, 434. doi: 10.1038/347434a0

Edwards PB, Wanjura WJ, Brown WV (1993) Selective herbivory by Christmas beetles in response to intraspecific variation in Eucalyptus. Oecologia 95, 551-557.

Egerton-Warburton LM, Ghisalberti EL, Considine JA (1998a) Infraspecific variability in the volatile leaf oils of Chamelaucium uncinatum (Myrtaceae). Biochemical Systematics and Ecology 26, 873-888. doi: 10.1016/S0305-1978(98)00029-5

Egerton-Warburton LM, Ghisalberti EL, Burton NC (1998b) Intergeneric hybridism between Chamelaucium and Verticordia (Myrtaceae) based on analysis of essential oils and morphology. Australian Journal of Botany 46, 201-208. doi: 10.1071/BT96125

Eisenreich W, Schwarz M, Cartayrade A, Arigoni D, Zenk MH, Bacher A (1998) The deoxyxylulose phosphate pathway of terpenoid biosynthesis in plants and microorganisms. Chemistry \& Biology $\mathbf{5}$, R221-R233. doi: 10.1016/S1074-5521(98)90002-3

Eschler BM, Pass DM, Willis R, Foley WJ (2000) Distribution of foliar formylated phloroglucinol derivatives amongst Eucalyptus species. Biochemical Systematics and Ecology 28, 813-824. doi: 10.1016/S0305-1978(99)00123-4

Eyles A, Davies NW, Yuan ZQ, Mohammed C (2003) Host responses to natural infection by Cytonaema sp. in the aerial bark of Eucalyptus globulus. Forest Pathology 33, 317-331 doi: 10.1046/j.1439-0329.2003.00332.x

Fadel H, Marx F, El-Sawy A, El-Ghorab A (1999) Effect of extraction techniques on the chemical composition and antioxidant activity of Eucalyptus camaldulensis var. brevirostris leaf oils. Zeitschrift fur Lebensmittel-Untersuchung und-Forschung. A, Food Research and Technology 208, 212-216. doi: $10.1007 / \mathrm{s} 002170050405$

Fernandez MA, Tornos MP, Garcia MD, de las Heras B, Villar AM, Saenz MT (2001) Anti-inflammatory activity of abietic acid a diterpene isolated from Pimenta racemosa var. grissea. Journal of Pharmacy and Pharmacology 53, 867-872. doi: $10.1211 / 0022357011776027$

Gershenzon J, Croteau R (1993) Terpenoid biosynthesis: the basic pathway and formation of monoterpenes, sesquiterpenes, and diterpenes. In 'Lipid metabolism in plants'. (Ed. TSJ Moore) pp. 339-388. (CRC Press: Boca Raton: FL).

Ghisalberti EL (1996) Bioactive acylphloroglucinol derivatives from Eucalyptus species. Phytochemistry 41, 7-22. doi: 10.1016/0031-9422(95)00484-X
Giamakis A, Kretsi O, Chinou I, Spyropoulos CG (2001) Eucalyptus camaldulensis: volatiles from immature flowers and high production of 1,8-cineole and beta-pinene by in vitro cultures. Phytochemistry 58, 351-355. doi: 10.1016/S0031-9422(01)00193-5

Guenther AB, Monson RK, Fall R (1991) Isoprene and monoterpene emission rate variability observations with Eucalyptus and emission rate algorithm development. Journal of Geophysical ResearchAtmospheres 96, 10799-10808.

Harder J, Foss S (1999) Anaerobic formation of the aromatic hydrocarbon $p$-cymene from monoterpenes by methanogenic enrichment cultures. Geomicrobiology Journal 16, 295-305. doi: $10.1080 / 014904599270550$

He C, Murray F, Lyons T (2000a) Monoterpene and isoprene emissions from 15 Eucalyptus species in Australia. Atmospheric Environment 34, 645-655. doi: 10.1016/S1352-2310(99)00219-8

He C, Murray F, Lyons T (2000b) Seasonal variations in monoterpene emissions from Eucalyptus species. Chemosphere-Global Change Science 2, 65-76. doi: 10.1016/S1465-9972(99)00052-5

Homer LE, Leach DN, Lea D, Slade LL, Henry RJ, Baverstock PR (2000) Natural variation in the essential oil content of Melaleuca alternifolia Cheel (Myrtaceae). Biochemical Systematics and Ecology 28, 367-382. doi: 10.1016/S0305-1978(99)00071-X

Hugueney P, Camara B (1990) Purification and characterization of farnesyl pyrophosphate synthase from Capsicum annuum. FEBS Letters 273, 235-238. doi: 10.1016/0014-5793(90)81093-4

Hume ID, Esson C (1993) Nutrients, antinutrients and leaf selection by captive koalas (Phascolarctos cinereus). Australian Journal of Zoology 41, 379-392. doi: 10.1071/ZO9930379

Iason G (2005) The role of plant secondary metabolites in mammalian herbivory: ecological perspectives. Proceedings of the Nutrition Society 64, 123-131. doi: 10.1079/PNS2004415

Iijima Y, Gang DR, Fridman E, Lewinsohn E, Pichersky E (2004) Characterization of geraniol synthase from the peltate glands of sweet basil. Plant Physiology 134, 370-379. doi: $10.1104 /$ pp. 103.032946

Ireland BF, Hibbert DB, Goldsack RJ, Doran JC, Brophy JJ (2002) Chemical variation in the leaf essential oil of Melaleuca quinquenervia (Cav.) S.T. Blake. Biochemical Systematics and Ecology 30, 457-470. doi: 10.1016/S0305-1978(01)00112-0

Johnstone PC (1984) Chemosystematic and morphometric relationships of populations of some peppermint eucalypts. PhD Thesis, Monash University, Melbourne.

Jones TGH (1937) Essential oils from the Queensland flora. X. Melaleuca linariifolia. Proceedings of the Royal Society of Queensland 48, $48-50$.

Jones RVH, Sutherland MD (1968) Terpenoid chemistry. XV. 1,5Dimethylcyclodeca-1,5,7-triene, the precursor of geijerene in Geijera parviflora. Australian Journal of Chemistry 21, 2255-2264.

Kearsley MJC, Whitham TG (1998) The developmental stream of cottonwoods affects ramet growth and resistance to galling aphids. Ecology 79, 178-191.

Kindle KL (1998) Amino-terminal and hydrophobic regions of the Chlamydomonas reinhardtii plastocyanin transit peptide are required for efficient protein accumulation in vivo. Plant Molecular Biology 38, 365-377. doi: 10.1023/A:1006025606330

Kindle KL, Lawrence SD (1998) Transit peptide mutations that impair in vitro and in vivo chloroplast protein import do not affect accumulation of the gamma-subunit of chloroplast ATPase. Plant Physiology 116, 1179-1190. doi: 10.1104/pp.116.3.1179

King DJ, Gleadow RM, Woodrow IE (2006) The accumulation of terpenoid oils does not incur a growth cost in Eucalyptus polybractea seedlings. Functional Plant Biology 33, 497-505. doi: 10.1071/FP05304 
Kliebenstein DJ, Lambrix VM, Reichelt M, Gershenzon J, Mitchell-Olds T (2001) Gene duplication in the diversification of secondary metabolism: tandem 2-oxoglutarate-dependent dioxygenases control glucosinolate biosynthesis in Arabidopsis. The Plant Cell 13, 681-693. doi: $10.2307 / 3871415$

Köllner TG, Schnee C, Gershenzon J, Degenhardt J (2004) The variability of sesquiterpenes emitted from two Zea mays cultivars is controlled by allelic variation of two terpene synthase genes encoding stereoselective multiple product enzymes. The Plant Cell 16, 1115-1131. doi: $10.1105 /$ tpc. 019877

Lassak EV, Southwell IA (1982) The steam volatile leaf oils of some species of Eucalyptus subseries Strictinae. Phytochemistry 21, 2257-2261. doi: 10.1016/0031-9422(82)85188-1

Lawler IR, Stapley J, Foley WJ, Eschler BM (1999) Ecological example of a conditioned food aversion in plant-herbivore interactions: the effect of terpenes of Eucalyptus leaves on feeding by common ringtail and brushtail possums. Journal of Chemical Ecology 25, 401-415. doi: 10.1023/A:1020863216892

Lawrence SD, Kindle KL (1997) Alterations in the Chlamydomonas plastocyanin transit peptide have distinct effects on in vitro import and in vivo protein accumulation. Journal of Biological Chemistry 272, 20357-20363. doi: $10.1074 / j b c .272 .33 .20357$

Lee CK (1998) Ursane triterpenoids from leaves of Melaleuca leucadendron. Phytochemistry 49, 1119-1122. doi: 10.1016/S0031-9422(97)01061-3

Lee LS, Brooks LO, Homer LE, Rossetto M, Henry RJ, Baverstock PR (2002) Geographic variation in the essential oils and morphology of natural populations of Melaleuca alternifolia (Myrtaceae). Biochemical Systematics and Ecology 30, 343-360. doi: 10.1016/S0305-1978(01)00092-8

Li H, Madden JL, Potts BM (1996) Variation in volatile leaf oils of the Tasmanian Eucalyptus species II. Subgenus Symphyomyrtus. Biochemical Systematics and Ecology 24, 547-569. doi: 10.1016/0305-1978(96)00040-3

Linhart YB, Thompson JD (1995) Terpene-based selective herbivory by Helix aspersa (Mollusca) on Thymus vulgaris (Labiatae). Oecologia 102, 126-132.

Loreto F, Forster A, Durr M, Csiky O, Seufert G (1998) On the monoterpene emission under heat stress and on the increased thermotolerance of leaves of Quercus ilex L. fumigated with selected monoterpenes. Plant, Cell \& Environment 21, 101-107. doi: 10.1046/j.1365-3040.1998.00268.x

Lowe RF, Russell MF, Southwell IA, Day J (2005) Astartea a new source of (+) (1S 5R)-myrtenal. Journal of Essential Oil Research 17, 683-685.

Lowman MD, Heatwole H (1992) Spatial and temporal variability in defoliation of Australian eucalypts. Ecology 73, 129-142. doi: $10.2307 / 1938726$

Lu S, Xu R, Jia JW, Pang JH, Matsuda SPT, Chen XY (2002) Cloning and functional characterization of a beta-pinene synthase from Artemisia апnua that shows a circadian pattern of expression. Plant Physiology 130, 477-486. doi: 10.1104/pp.006544

Lücker J, Bouwmeester HJ, Schwab W, Blaas J, van der Plas LH, Verhoeven HA (2001) Expression of Clarkia S-linalool synthase in transgenic petunia plants results in the accumulation of S-linalyl-betaD-glucopyranoside. The Plant Journal 27, 315-324. doi: $10.1046 / j .1365-313 x .2001 .01097 . x$

Lücker J, EI Tamer MK, Schwab W, Verstappen FWA, van der Plas LHW, Bouwmeester HJ, Verhoeven HA (2002) Monoterpene biosynthesis in lemon (Citrus limon). cDNA isolation and functional analysis of four monoterpene synthases. European Journal of Biochemistry 269, 3160-3171.

doi: $10.1046 / \mathrm{j} .1432-1033.2002 .02985 . \mathrm{x}$
Lupien S, Karp F, Wildung M, Croteau RB (1999) Regiospecific Cytochrome P450 limonene hydroxylases from mint (Mentha) species: cDNA isolation characterization and functional expression of (-)-4S-limonene-3hydroxylase and (-) 4S-limonene-6-hydroxylase. Archives of Biochemistry and Biophysics 368, 181-192. doi: 10.1006/abbi.1999.1298

Mansfield S, Withers TM, Gous SF, Potter KJB, Kriticos DJ, Watson MC, Kimberley MO (2006) Potential of selective insecticides for managing Uraba lugens (Lepidoptera: Nolidae) on eucalypts. Journal of Economic Entomology 99, 780-789.

Martin DM, Bohlmann J (2004) Identification of Vitis vinifera (-)-alphaterpineol synthase by in silico screening of full-length cDNA ESTs and functional characterization of recombinant terpene synthase. Phytochemistry 65, 1223-1229.

Martin DM, Faldt J, Bohlmann J (2004) Functional characterization of nine Norway spruce TPS genes and evolution of Gymnosperm terpene synthases of the TPS-d subfamily. Plant Physiology 135, 1908-1927. doi: $10.1104 / p p .104 .042028$

Mastelic J, Jerkovic I (2003) Application of co-distillation with superheated pentane vapour to the isolation of unstable essential oils. Flavour and Fragrance Journal 18, 521-526. doi: 10.1002/ffj.1261

Mayer R (1990) Flavonoids from Leptospermum scoparium. Phytochemistry 29, 1340-1342. doi: 10.1016/0031-9422(90)85462-O

McConkey ME, Gershenzon J, Croteau RB (2000) Developmental regulation of monoterpene biosynthesis in the glandular trichomes of peppermint. Plant Physiology 122, 215-224. doi: $10.1104 /$ pp.122.1.215

Mercke P, Crock J, Croteau RB, Brodelius PE (1999) Cloning expression and characterization of epi-cedrol synthase a sesquiterpene cyclase from Artemisia annua L. Archives of Biochemistry and Biophysics 369, 213-222. doi: 10.1006/abbi.1999.1358

Milborrow BV (2001) The pathway of biosynthesis of abscisic acid in vascular plants: a review of the present state of knowledge of ABA biosynthesis. Journal of Experimental Botany 52, 1145-1164. doi: 10.1093/jexbot/52.359.1145

Miller B, Oschinski C, Zimmer W (2001) First isolation of an isoprene synthase gene from poplar and successful expression of the gene in Escherichia coli. Planta 213, 483-487. doi: $10.1007 /$ s004250100557

Molina A, Reigosa MJ, Carballeira A (1991) Release of allelochemical agents from litter throughfall and topsoil in plantations of Eucalyptus globulus Labill in Spain. Journal of Chemical Ecology 17, 147-160. doi: 10.1007/BF00994428

Moore BD, Wallis IR, Pala-Paul J, Brophy JJ, Willis RH, Foley WJ (2004) Antiherbivore chemistry of Eucalyptus - Cues and deterrents for marsupial folivores. Journal of Chemical Ecology 30, 1743-1769. doi: 10.1023/B:JOEC.0000042399.06553.c6

Morrow PA, Fox LR (1980) Effects of variation in Eucalyptus essential oil yield on insect growth and grazing damage. Oecologia 45, 209-219. doi: 10.1007/BF00346462

Nakagiri T, Lee J-B, Hayashi T (2005) cDNA cloning functional expression and characterization of ent-copalyl diphosphate synthase from Scoparia dulcis L. Plant Science 169, 760-767. doi: 10.1016/j.plantsci.2005.05.028

Nishimura K, Shinoda N, Hirose Y (1969) A new sesquiterpen, bicyclogermacrene. Tetrahedron Letters 10, 3097-3100. doi: 10.1016/S0040-4039(01)88358-1

Ohnuma S, Koyama T, Ogura K (1989) Kinetic studies on the prenyl chain elongation by undecaprenyl diphosphate synthase with artificial substrate homologues. FEBS Letters 257, 71-74. doi: 10.1016/0014-5793(89)81789-2

Penfold AR (1925) Essential oils of Melaleuca linarifolia (Smith) and M. alternifolia (Cheel). Journal and Proceedings of the Royal Society of New South Wales 59, 306-324. 
Penfold AR, Morrison FR (1927) The occurrence of a number of varieties of Eucalyptus dives as determined by chemical analyses of the essential oils. Journal and Proceedings of the Royal Society of New South Wales 61, 54-67.

Penfold AR, Morrison FR (1937) The occurrence of a number of varieties of Eucalyptus radiata (E. numerosa) as determined by chemical analyses of the essential oils. Journal and Proceedings of the Royal Society of New South Wales 70, 375-377.

Penfold AR, Willis JL (1953) Physiological forms of Eucalyptus citriodora Hooker. Nature 171, 883-884. doi: 10.1038/171883b0

Perry NB, Brennan NJ, Van Klink JW, Harris W, Douglas MH, McGimpsey JA, Smallfield BM, Anderson RE (1997) Essential oils from New Zealand manuka and kanuka: chemotaxonomy of Leptospermum. Phytochemistry 44, 1485-1494.

doi: 10.1016/S0031-9422(96)00743-1

Pichersky E, Noel JP, Dudareva N (2006) Biosynthesis of plant volatiles: nature's diversity and ingenuity. Science $\mathbf{3 1 1}, 808-811$. doi: 10.1126/science. 1118510

Plomion C, Yani A, Marpeau A (1996) Genetic determinism of delta 3 -carene in maritime pine using RAPD markers. Genome 39, $1123-1127$.

Prosser IM, Adams RJ, Beale MH, Hawkins ND, Phillips AL, Pickett JA, Field LM (2006) Cloning and functional characterisation of a cismuuroladiene synthase from black peppermint (Mentha $\times$ piperita) and direct evidence for a chemotype unable to synthesise farnesene. Phytochemistry 67, 1564-1571. doi: $10.1016 /$ j.phytochem.2005.06.012

Qi X, Bakht S, Leggett M, Maxwell C, Melton R, Osbourn A (2004) A gene cluster for secondary metabolism in oat: implications for the evolution of metabolic diversity in plants. Proceedings of the National Academy of Sciences, USA 101, 8233-8238. doi: 10.1073/pnas.0401301101

Rasmann S, Kollner TG, Degenhardt J, Hiltpold I, Toepfer S, Kuhlmann U, Gershenzon J, Turlings TCJ (2005) Recruitment of entomopathogenic nematodes by insect-damaged maize roots. Nature 434, 732-737. doi: 10.1038 /nature 03451

Ringer KL, Davis EM, Croteau RB (2005) Monoterpene metabolism. Cloning expression and characterization of (-)-isopiperitenol/(-)-carveol dehydrogenase of peppermint and spearmint. Plant Physiology 137, 863-872. doi: 10.1104/pp.104.053298

Russell M, Southwell IA (2002) Monoterpenoid accumulation in Melaleuca alternifolia seedlings. Phytochemistry 59, 709-716. doi: 10.1016/S0031-9422(02)00038-9

Santos GG, Alves JCN, Rodilla JML, Duarte AP, Lithgow AM, Urones /surname >JG (1997) Terpenoids and other constituents of Eucalyptus globulus. Phytochemistry 44, 1309-1312. doi: 10.1016/S0031-9422(96)00680-2

Schepmann HG, Pang J, Matsuda SPT (2001) Cloning and characterization of Ginkgo biloba levopimaradiene synthase which catalyzes the first committed step in ginkgolide biosynthesis. Archives of Biochemistry and Biophysics 392, 263-269. doi: 10.1006/abbi.2001.2438

Sefidkon F, Dabiri M, Rahimi-Bidgoly A (1999) The effects of distillation methods and stage of plant growth on the essential oil content and composition in Tymus kotschyanus. Flavour and Fragrance Journal 14, 405-408.

doi: 10.1002/(SICI)1099-1026(199911/12)14:6<405::AID-FFJ853>3.0 $\mathrm{CO} ; 2-\mathrm{M}$

Schwab W (2003) Metabolome diversity: too few genes too many metabolites? Phytochemistry 62, 837-849. doi: 10.1016/S0031-9422(02)00723-9

Sharkey TD, Yeh S, Wiberley AE, Falbel TG, Gong D, Fernandez DE (2005) Evolution of the isoprene biosynthetic pathway in Kudzu. Plant Physiology 137, 700-712. doi: 10.1104/pp.104.054445
Shelton DA, Leach DN, Henry RJ (2004a) Isopentenyl pyrophosphate isomerases from Melaleuca alternifolia (Cheel) and their role in isoprenoid biosynthesis. Journal of Horticultural Science \& Biotechnology 79, 289-292.

Shelton D, Zabaras D, Chohan S, Wyllie SG, Baverstock P, Leach D, Henry R (2004b) Isolation and partial characterisation of a putative monoterpene synthase from Melaleuca alternifolia. Plant Physiology and Biochemistry 42, 875-882. doi: 10.1016/j.plaphy.2004.10.010

Shepherd M, Chaparro JX, Teasdale R (1999) Genetic mapping of monoterpene composition in an interspecific eucalypt hybrid. Theoretical and Applied Genetics 99, 1207-1215. doi: $10.1007 / \mathrm{s} 001220051326$

Shimada T, Endo T, Fujii H, Hara M, Ueda T, Kita M, Omura M (2004) Molecular cloning and functional characterization of four monoterpene synthase genes from Citrus unshiu Marc. Plant Science 166, 49-58. doi: 10.1016/j.plantsci.2003.07.006

Shimada T, Endo T, Fujii H, Hara M, Omura M (2005) Isolation and characterization of (E)-beta-ocimene and 1,8-cineole synthases in Citrus unshiu Marc. Plant Science 168, 987-995. doi: 10.1016/j.plantsci.2004.11.012

Silver GM, Fall R (1995) Characterization of aspen isoprene synthase an enzyme responsible for leaf isoprene emission to the atmosphere. Journal of Biological Chemistry 270, 13010-13016. doi: $10.1074 / \mathrm{jbc} .270 .51 .30384$

Simmons D, Parsons RF (1976) Analysis of a hybrid swarm involving Eucalyptus crenulata and E. ovata using leaf oils and morphology. Biochemical Systematics and Ecology 4, 97-101. doi: 10.1016/0305-1978(76)90019-3

Simmons D, Parsons RF (1987) Seasonal variation in the volatile leaf oils of two Eucalyptus species. Biochemical Systematics and Ecology 15, 209-215. doi: 10.1016/0305-1978(87)90021-4

Smith MW, Yamaguchi S, Ait-Ali T, Kamiya Y (1998) The first step of gibberellin biosynthesis in pumpkin is catalyzed by at least two copalyl diphosphate synthases encoded by differentially regulated genes. Plant Physiology 118, 1411-1419. doi: $10.1104 / \mathrm{pp} .118 .4 .1411$

Southwell IA (1970) New occurrence of hedycaryol, the precursor of elemol, in Phebalium ozothamnoides (Rutaceae). Phytochemistry 9, 2243-2245. doi: 10.1016/S0031-9422(00)85393-5

Southwell IA (1978) 'Essential oil content of koala food trees'. In 'The koala: proceedings of the Taronga symposium'. (Ed. TJ Bergin) pp. 62-74. (Royal Zoological Society of NSW: Sydney)

Southwell IA, Lowe R (1999) 'Tea tree: the genus Melaleuca.' (CRC Press: Boca Raton, FL)

Southwell IA, Russell MF (2002) Volatile oil comparison of cotyledon leaves of chemotypes of Melaleuca alternifolia. Phytochemistry 59, 391-393. doi: 10.1016/S0031-9422(01)00405-8

Southwell IA, Stiff IA (1989) Ontogenetical changes in monoterpenoids of Melaleuca alternifolia leaf. Phytochemistry 28, 1047-1051. doi: 10.1016/0031-9422(89)80180-3

Southwell IA, Stiff IA (1990) Differentiation between Melaleuca alternifolia and M. linariifolia by monoterpenoid comparison. Phytochemistry 29, 3529-3533. doi: 10.1016/0031-9422(90)85269-L

Starks CM, Back K, Chappell J, Noel JP (1997) Structural basis for cyclic terpene biosynthesis by tobacco 5-epi-aristolochene synthase. Science 277, 1815-1820. doi: 10.1126/science.277.5333.1815

Staudt M, Joffre R, Rambal S (2003) How growth conditions affect the capacity of Quercus ilex leaves to emit monoterpenes. New Phytologist 158, 61-73.

Stone C, Bacon PE (1994) Relationships among moisture stress insect herbivory foliar cineole content and the growth of river red gum Eucalyptus camaldulensis. Journal of Applied Ecology 31, 604-612. doi: $10.2307 / 2404151$ 
Sun TP, Kamiya Y (1994) The Arabidopsis GA1 locus encodes the cyclase ent-kaurene synthetase A of gibberellin biosynthesis. The Plant Cell 6, 1509-1518. doi: 10.2307/3869986

Suomela J, Ayres MP (1994) Within-tree and among-tree variation in leaf characteristics of mountain birch and its implications for herbivory. Oikos 70, 212-222. doi: $10.2307 / 3545632$

Thumma BR, Nolan MR, Evans R, Moran GF (2005) Polymorphisms in cinnamoyl CoA reductase (CCR) are associated with variation in microfibril angle in Eucalyptus spp. Genetics 171, 1257-1265. doi: $10.1534 /$ genetics. 105.042028

Toyota M, Koyama H, Mizutani M, Asakawa Y (1996) (-)-ent-Spathulenol isolated from liverworts is an artefact. Phytochemistry 41, 1347-1350. doi: 10.1016/0031-9422(95)00798-9

Wang H, Fujimoto Y (1993) Triterpene esters from Eucalyptus tereticornis. Phytochemistry 33, 151-153. doi: 10.1016/0031-9422(93)85113-6

Weston RJ (1984) Composition of essential oil from leaves of Eucalyptus delegatensis. Phytochemistry 23, 1943-1945. doi: 10.1016/S0031-9422(00)84946-8

Whittington DA, Wise ML, Urbansky M, Coates RM, Croteau RB, Christianson DW (2002) Bornyl diphosphate synthase: structure and strategy for carbocation manipulation by a terpenoid cyclase. Proceedings of the National Academy of Sciences, USA 99, 15375-15380. doi: 10.1073/pnas.232591099

Wildung MR, Croteau RB (2005) Genetic engineering of peppermint for improved essential oil composition and yield. Transgenic Research 14, 365-372. doi: 10.1007/s11248-005-5475-2

Wildy DT, Pate JS, Bartle JR (2000) Variations in composition and yield of leaf oils from alley-farmed oil mallees (Eucalyptus spp.) at a range of contrasting sites in the Western Australian wheatbelt. Forest Ecology and Management 134, 205-217. doi: 10.1016/S0378-1127(99)00258-3

Williams DC, McGarvey DJ, Katahira EJ, Croteau RB (1998) Truncation of limonene synthase preprotein provides a fully active 'Pseudomature' form of this monoterpene cyclase and reveals the function of the amino-terminal arginine pair. Biochemistry 37, 12213-12220. doi: 10.1021/bi980854k
Wink M (2003) Evolution of secondary metabolites from an ecological and molecular phylogenetic perspective. Phytochemistry 64, 3-19. doi: 10.1016/S0031-9422(03)00300-5

Wise ML, Savage TJ, Katahira E, Croteau RB (1998) Monoterpene synthases from common sage (Salvia officinalis) - cDNA isolation characterization and functional expression of $(+)$-sabinene synthase 1,8-cineole synthase and (+)-bornyl diphosphate synthase. Journal of Biological Chemistry 273, 14891-14899. doi: 10.1074/jbc.273.24.14891

Yamakoshi Y, Murata M, Shimizu A, Homma S (1992) Isolation and characterization of macrocarpals B-G antibacterial compounds from Eucalyptus macrocarpa. Bioscience, Biotechnology, and Biochemistry 56, 1570-1576.

Yang T, Li J, Wang HX, Zeng Y (2005) A geraniol-synthase gene from Cinnamomum tenuipilum. Phytochemistry 66, 285-293. doi: 10.1016/j.phytochem.2004.12.004

Yoshioka H, Yamada N, Doke N (1999) cDNA cloning of sesquiterpene cyclase and squalene synthase and expression of the genes in potato tuber infected with Phytophthora infestans. Plant \& Cell Physiology 40, 993-998.

Zabaras D, Wyllie SG (2002) Rearrangement of $p$-menthane terpenes by Carboxen during HS-SPME. Journal of Separation Science 25, 685-690. doi: 10.1002/1615-9314(20020701)25:10/11<685::AID-JSSC685>3.0. $\mathrm{CO} ; 2-9$

Zavala-Paramo G, Chavez-Moctezuma MP, Garcia-Pineda E, Yin S, Chappell J, Lozoya-Gloria E (2000) Isolation of an elicitor-stimulated 5-epiaristolochene synthase gene ( $g P E A S 1)$ from chili pepper (Capsicum annuum). Physiologia Plantarum 110, 410-418. doi: 10.1034/j.1399-3054.2000.1100316.x

Manuscript received 1 August 2007, accepted 24 December 2007 